\title{
Review on Aluminum and Steel Semi-rigid Connections Behavior Design Model
}

\author{
Guy Oyéniran ADEOTI ${ }^{1}$, Ernesto Cabral HOUEHANOU ${ }^{2, *}$, Huihuan MA $^{3}$, \\ Éric Adéchina ALAMOU ${ }^{1}$, Feng FAN ${ }^{3}$

\footnotetext{
${ }^{1}$ National Higher School of Civil Engineering, National University of Sciences, Technologies, Engineering and Mathematics, Department of Zou, Benin
} \\ ${ }^{2}$ Higher National Institute of Industrial Technology, National University of Sciences, Technologies, Engineering and Mathematics, Department of Mono, Benin \\ ${ }^{3}$ School of Civil Engineering, Harbin Institute of Technology, China
}

\begin{abstract}
Received October 16, 2020; Revised December 30, 2020; Accepted January 20, 2021
Cite This Paper in the following Citation Styles

(a): [1] Guy Oyéniran ADEOTI, Ernesto Cabral HOUEHANOU, Huihuan MA, Éric Adéchina ALAMOU, Feng FAN, "Review on Aluminum and Steel Semi-rigid Connections Behavior Design Model," Civil Engineering and Architecture, Vol. 9, No. 1, pp. 184-205, 2021. DOI: 10.13189/cea.2021.090116.

(b): Guy Oyéniran ADEOTI, Ernesto Cabral HOUEHANOU, Huihuan MA, Éric Adéchina ALAMOU, Feng FAN, (2021). Review on Aluminum and Steel Semi-rigid Connections Behavior Design Model. Civil Engineering and Architecture, 9(1), 184-205. DOI: 10.13189/cea.2021.090116.
\end{abstract}

Copyright $\odot 2021$ by authors, all rights reserved. Authors agree that this article remains permanently open access under the terms of the Creative Commons Attribution License 4.0 International License

\begin{abstract}
Several research reports agree on the influence of joint rotational behavior on the stability of space frames. One must therefore consider it in space structures study. Joint rotational behavior is generally considered in space structures study by means of its moment-rotation behavior curve. Models such as analytical, empirical, experimental, informational, mechanical and numerical mostly are used to determine joint mechanical behavior. This review paper presents an overview of available methods for the prediction of semi rigid connections behavior of under both static and dynamic loads. Advantages, disadvantages, and principal characteristics of each model stretched out. The modeling of joint behavior in studying space structures is associated with a mathematical representation model of the joint moment-rotation curve. Several models, linear, bilinear, multilinear and nonlinear representations are developed through the years to picture accurately the joints moment rotation behavior. The most precise representation applies continuous nonlinear functions, even though the multilinear representation is generally used for mechanical models. Using test data on aluminum and steel bolted connections conducted at Harbin Institute of Technology a simple stable quartic polynomial model is proposed to represent the behavior of the connections. In addition, Three others models are also proposed, including an Odd power Polynomial Model as proposed by Frye \& Morris Model, a three parameter Power Model in accordance to the Kishi \& Chen Model, and a four-parameter exponential model in line with the Yee \& Melchers Model. These three models
\end{abstract}

are compared with the simple quartic polynomial model proposed in this paper. As a result, the proposed connection design model, independent of test data, can be used directly by designers to assess semi-rigid, bolted connection behavior in Space Structures. The present work will give support to engineers for easy and accurate choice of the joint behavior prediction model and portrait correctly the behavior of the joints for best use in semi-rigid space structures construction.

Keywords Semi-rigid Joints, Joint Prediction Model, Bolted Connections, Aluminum Material

\section{Introduction}

The incorporation of the effects of joint flexibility in the assessments of the structural performance of steel frame structures requires a knowledge of the connection moment-rotation $M-\theta$ characteristics. The prediction of connection behavior is the first step in designing or modeling of semi-rigid connections as structural elements and therefore, by extension in the stability analysis of Space Structures. Many researchers have presented the details of connection behavior. Nethercot \& Zandonini reviewed the methods available for prediction of beamto-column joint behavior [1,2]. The work [1,2] particularly consisted in identifying and reviewing available methods for the prediction of $M-\theta$ curves and techniques for representing them in mathematical and/or analytical form; Embracing 
the empirical curve fitting of experimental data, the use of simplified analytical, behavioral and mechanical models, and full numerical analysis. They then classified methods of prediction into four categories:

- Prediction using mathematical expressions,

- Prediction by simplified analytical models,

- Prediction by mechanical models and

- Prediction by finite element analysis.

For the purpose of expressing the moment-rotation $(M-\theta)$ behavior of various types of connections, several mathematical expressions are used in literature, being developed primarily from experimental studies. Some of these mathematical models are not suitable for the prediction of semi-rigid connection behavior. They only represent the behavior of connections based on experimental and numerical results. Yet, several other, parameters are related to the physical and mechanical properties of the connections and those parameters can be found analytically. Early mathematical models proposed by John Charles Rathbun (1936), Monforton et. al (1963) and Lightfoot et. al (1974) used a linear moment-rotation $M-\theta$ model for the description of the connection behavior for the whole range of the connection deformation [3-5].

John Charles Rathbun (1936) in working on the elastic properties of riveted connections reported a series of tests on beamto-column joint to determine the relationship between the angular change in riveted beam connections and the moment inducing these changes (Moment-rotation relationship). Tests of 18 connections of the three most common types of steel beams formed the basis of the work and showed how the test information may be applied to design not only for single beams, but also in the investigation of the stresses in riveted frames. Rathbun's work also showed the necessary changes to be made in the formulas in several method of analysis in order to allow the elasticity of the riveted connections.

Monforton et. al's (1963) study was mainly based on matrix analysis of semi-rigid connected frames and Lightfoot et. al (1974) worked on the elastic analysis of frameworks with elastic connections. A linear model can only be applicable in a limited range of the initial rotation, seeing that non-linearity in the connection behavior normally occurs in the first stage of the loading. The piecewise linear model is an extended form of linear model that is composed of a series of straight-fine segments.

Later on, several of the mathematical models (mathematical equations) in the form of linear, bilinear, trilinear, polynomial, spline, exponential, and power functions have been proposed (Frye \& Morris (1975), Goverdhan (1983), Ang \& Morris (1984), Nethercot (1985), Kishi \& Chen (1986), Yee $\&$ Melchers (1986), Chen and Lui (1991), and computer programs PRCONN, Chen and Toma (1994), Chen et.al (2011), etc. are available [6-16].

Lionberger et.al (1969) working on the dynamic response of frames with nonrigid connectors and Romstad et.al (1970) analysing frames with partial connection rigidity proposed a bilinear model [17, 18]. In 1981 Moncarz and Gerstl worked on steel frames with nonlinear connections and proposed a trilinear model. The bilinear, trilinear and multilinear models are examples of the piecewise linear model. The piecewise model, besides the initial stiffness requirement, can also satisfy the strength requirement of the connection [19]. However, the researches of Lorenz Robert and Chen (1993) and Al-Bermani et.al (1994) have stated that the abrupt changes in the connection stiffness at the transition points of the linear segments make their practical use difficult $[20,21]$.

Al-Bermani et. al (1994) presented a model requiring four parameters to describe simulating the hysteretic momentrotation $\left(M-\theta_{r}\right)$ behaviour of flexible joints under cyclic and dynamic loading conditions. This model requires four parameters to describe and using existing test data for different types of connections, he evaluated these parameters. The proposed model was cast into a two-node zero length connection element and used to model the nonlinear response of flexibly jointed frames. The work showed that the presence of flexible joints alters the vibration characteristics of the structure depending on the excitation frequency can either dampen or magnify the structures' response [21].

In 1980 Jones Stephen Wynford et. al made a review of all available experimental data relating to the moment versus inplane rotational behavior of practical beam-to-column connection types as used in steel frames which has clearly shown that all forms of connections possess some stiffness which act as partial restraint to the column's ends. Moreover this restraint has been found to be a non-linear function of connection deformation. Methods of mathematically describing connection data have been reviewed and an improved representation based on the use of cubic B-splines proposed [22]. However, this model requires large numbers of sampling data for the formulation process. In other words, the cubic B-spline model is effectively a curve fitting technique. This possesses the advantage that, it will not give an (incorrect) negative connection stiffness. Using this technique to model connection behavior a computer program for the maximum strength analysis of steel columns has been written based on Newton-Raphson incremental finite element approach and it incorporates features such as initial lack of straightness and spread of yield through the cross-section including the effects of residual stresses.

Three years later, he traced the history of research relating to the behavior of steel beam-to-column connections starting from early developments in 1917 and focused his attention on moment-rotation characteristics as this is the most important influence on the response of either individual members or complete frames. He then identified the nonlinear nature of this characteristic and methods of representing moment-rotation curves for subsequent use in analytical procedures were discussed. A Review of all available test data, was made again for use as a starting point for both further studies of connection behavior and as the basis for investigations of the effects of semi-rigid connections on structural response [23].

In 1975 John Frye \& Glenn Morris presented a procedure for analyzing steel frames with any combination of pinned connections, fixed connections, connections with any specified flexibility characteristics, or any of seven commonly used connection types. Frye et. al proposed a polynomial model to evaluate 
the behavior of connections. In this model, the $M-\theta$ behavior is represented by an odd-power polynomial. The method was outlined for expressing, in a nondimensional form, the moment-rotation characteristics for all connections of a given type. The dimensionless relationships were listed for the commonly used structural steel framing connection types. The incorporation of connection deformations into a linear structural analysis, by modifying the stiffness matrix and fixed-end-force vectors for each member, was demonstrated and an iterative nonlinear analysis procedure was described in which, repeated modifications were made to assume flexibility characteristics for all connections in a structure. When a suitable set of connection flexibility characteristics has been achieved, a single analysis can be performed to determine the correct structural deflections and internal forces.

Later in 1986, Lui \& Chen presented a method for analysing the behaviour of flexibly-connected plane steel frames. They used two types of elements in the analysis procedure: the beam-column (frame) element and the connection element. The beam-column element formulation was based on an updated Lagrangian approach. Allowance for the coupling effect of axial force and bending moments, as well as for the formation of plastic hinges in the member, was made for beamcolumn element. The nonlinear behavior of the connection was modelled by an exponential function to curve fit the experimental $M-\theta$ data. This model represents the monotonic non-linear connection behavior well. Both the loading and unloading responses of the connections were taken into consideration in the formulation. The monotonic load-deflection response of frames with flexible connections was traced using an incremental load control Newton-Raphson iterative technique. Based on sub-assemblage and the frame analyses, they concluded that connection flexibility has an important influence on frame behavior [24].

In 1987 Kishi \& Chen did a refined work on the [24] exponential model to accommodate sharp changes in the slope of the $M-\theta$ curve. However, in 1996 Chen \& Goto et. al stated that if there are some sharp changes in the slope of the $M-\theta$ curve this model could not represent it adequately $[25,26]$.

Yee \& Melchers (1986), and Wu \& Chen (1990) also reported an exponential model. Yee \& Melchers model, presented in 1986 was a physically based mathematical model that can predict the moment-rotation relationships of bolted extended end-plate eave connections, using the connection dimensions as inputs. The model recognized the bounds within which the relationship must lie by including three parameters: the initial (elastic) stiffness, the plastic moment capacity and the strain-hardening stiffness of the connection. A constant was also added. The Wu \& Chen model (1990), a threeparameter exponential model that involved parameters such as: initial connection stiffness, ultimate moment capacity and a shape parameter to represent the behavior of top- and seatangles with or without double web-angle connections. Two of the parameters, namely, the initial stiffness and the mechanism moment, were theoretically defined and extensively compared with those measured from connection test curves. The third parameter, the shape parameter, was determined by a curve-fitting with the connection tests and was statistically represented by a simple linear expression. As a result, the proposed connection design model became independent of test data and could be used directly by designers to assess connection behavior in a semi-rigid frame analysis [27].

Many researchers also proposed models known as power model. In 1984, Ang \& Morris presented a procedure for analyzing three-dimensional rectangular steel frames that incorporate any of the five commonly used beam-column connection types. They described a method for expressing the $M-\theta$ behavior of connections of a given type in terms of a single standardized Ramberg-Osgood function in the power form composed of four parameters. The method involved an examination of experimental information on the moment-rotation behavior of a given connection type to determine the influence of various size parameters and it has been used to generate standardized moment-rotation functions for five common connection types. An iterative, successive approximation structural analysis procedure was described. In this, repeated approximations were made to assumed stiffness characteristics of all connections in the structure.

Colson André (1991) proposed models using initial connection stiffness, ultimate moment capacity and a shape parameter as parameters. The semi-rigid, and nonlinear behavior of the connections in structures, being recognized, Colson André found it is necessary to have mathematical models in order to allow exact frame analysis with computer programs. He then proposed a model based on physical parameters and verified, a priori, the thermodynamics principles. Energy dissipation, associated with nonlinearity, was considered as the main phenomenon. The model was established in the uni-dimensional case -moment and rotation- which, according to him was the most usual and the most interesting in view of the cheaper design. The extension to the more general case (six degrees of freedom) was introduced with the same concepts and emphasized on predictable feature of the model in comparison with other curve-fitting techniques [28].

The simplified analytical models have also been used for the prediction of the connection behavior by Nethercot \& Zandonini. The usual approach in this methods involved:

- Observation of test behavior to identify the major sources of deformation in the connection,

- Elastic analysis of the initial loading phase, concentrating on the key components, to predict initial connection stiffness,

- Plastic mechanism analysis for the key components to predict ultimate moment capacity,

- Verification of the resulting equations with test data and

- Description of the connection behavior by curve fitting using the calculated initial stiffness and ultimate moment capacity values in suitable expressions.

Krishnamurthy Natarajan et. al (1979), Krishnamurthy (1980), Kukreti et. al (1987), Bahaari \& Sherbourne (1994) and Sherbourne \& Bahaari (1994) reported analytical studies of beam-to-column connection behavior using the finite element 
method. The results of these studies indicate that the finite element method can be used for the estimation of the connection behavior and it can be used as a tool to develop constitutive relationship curves [29-33].

However, in 1996, Chen et. al esteemed that the finite element approaches are unacceptable for practical use because cumbersome calculations are required for the consideration of the material and geometrical non-linearities. In fact, the nonlinearity of the analysis is not only due to the geometric and material non-linearities but is also caused by contact conditions. Contact conditions have been shown to lead to severe non-linearities and convergence difficulties. Notwithstanding, in 1989, Nethercot recognized that, in the face of substantial and continuous progress, some of the requirements for the accurate simulation of joint response appear, as yet, to be unsolved.

Latterly, Abdalla \& Stavroulakis (1995), Chenaghlou \& Nooshin (1996) and Anderson et. al (1997) used artificial neural networks methods for the prediction of joint behavior [3436]. Wong \& Mak (1993) and Ren \& Beards (1995) also used system identification methods for the prediction of joint behavior [37, 38].

The connection models used so far represent the behavior under monotonic loading. In addition to these models, models for cyclic loading have also been presented in view of the necessity to analyze the behavior of semi-rigidly jointed structures subject to seismically induced loads or alternating wind loads. In this category, several works can be mentioned, namely: Egor Popov \& Bruce Pinkney (1969), Mazzolani (1988), Yoshiaki Goto et al. (1991), Al-Bermani et al. (1994), and F. M. Mazzolani \& S. Mazzolani (1995) [39-42].

\section{Mathematical Expressions of avail- able models}

As mentioned in section 1, suitable methods evolved through various research capable to investigate and predict moment rotation behavior of semi-rigid connections. They included mathematical expressions comprising curve-fitting models, simplified analytical models, mechanical models, and detailed 3D finite element models well elaborated to track down the complex behavior of the connections. Most of connections display a nonlinear moment-rotation characteristic that falls between the two extreme cases of ideally pinned and fully rigid connections which are purely a theoretical behaviors. It is quite tough to analyze these connections by a strike and exact mathematical procedure. As a consequence, the analyses of connection behavior used in practical design are approximate with stringent simplification. Mathematical representations of the momentrotation curve are necessary to account the record of the behavior of a joint in the overall analysis of a structure. Mathematical representations are done by different relationships and levels of precision. Various representations are used in literature: linear representation, bilinear representation, Trilinear (multilinear) representation, and nonlinear representation. The moment-rotation curve can be represented mathematically in one of two ways [43, 44]:
- depending on parameters with clear physical meaning such as stiffness, resistance and a shape factor;

- based on no clear physical meaning as it is derived from regression analysis, called curve-fitting formulations.

\subsection{Linear model}

The linear models use the initial stiffness $K_{i}$ to represent the connection behavior for its entire range of loading. It is the simplest to use but the least accurate because it overestimates the rigidity of the joint [45-47]. It is represented by the expression:

$$
M=K_{i} \theta_{r}
$$

\subsection{Bilinear model}

A bilinear model has a relatively shallow second slope at some kind of transition moment. It uses three parameters to represent the $M-\theta$ behavior of the connection: rotational stiffness $K_{i}$; plastic moment $M_{P}$; and plastic rotational stiffness $\left(K_{P}\right.$ of the connection. Implemented in finite element analysis (FEA) programs, it has a sharp change in rigidity and the intersection of the two curves [48-50]. It is represented by the expression:

$$
M= \begin{cases}K_{i} \theta_{r} & \text { For } M \leq M_{P} \\ K_{P} \theta_{r} & \text { For } M>M_{P}\end{cases}
$$

\subsection{The piecewise linear model}

The piecewise linear model (multilinear models)utilizes a series of straight segments to approximate the nonlinear moment-rotation curves. This model was proposed as a solution to the problem of the bilinear model. Moncarz \& Gerstle use this representation with five parameters, namely: rotational stiffness $K_{i}$; first yielding moment $M_{i}$; post-yielding rotational stiffness $K_{j}$; plastic moment $M_{P}$; and plastic rotational stiffness $K_{P}$ of the connection [51-55]. It is represented by the expression:

$$
M= \begin{cases}K_{i} \theta_{r} & \text { for } M \leq M_{j} \\ K_{j} \theta_{r} & \text { for } M_{j}<M<M_{P} \\ K_{P} \theta_{r} & \text { for } M_{P} \leq M\end{cases}
$$

These linear models are easy to use but the jumps in stiffness at the transition points make them almost unwelcome. 
Eurocode 3 proposed a representation divided into three segments, but for elastic-plastic analysis, a simplified bilinear model is proposed. The first segment of the curve has the linear behavior of equation 2.1 up to the moment value of $2 / 3 M_{R d}$, where $M_{R d}$, is the design value of the joint plastic moment $M_{P}$. The second segment is nonlinear according to equation 2.4 in the range of $2 / 3 M_{R d}<M<M_{R d}$.

$$
M=\frac{K_{i}}{\left(1.5 \frac{M}{M_{R d}}\right)^{\xi}} \theta_{r}
$$

where $\xi$ depends on the [44]:

$$
\xi=\left\{\begin{array}{l}
2.7 \text { welded, bolted end-plate } \\
\text { and base-plate connections } \\
3.1 \text { bolted angle flange cleats }
\end{array}\right.
$$

The last segment is a straight horizontal line representing the plastic behavior $M=M_{R d}$.

\subsection{Nonlinear model}

The Nonlinear modelis considered so far as the most accurate model. It was proposed in 1943 by Ramberg \& Osgood and represented by three parameters: rotational stiffness $K_{i}$, rotation $\theta_{r}$ of the connection, and the shape factor $n$ which describes the knee of the moment-rotation curve. The curve becomes bilinear with elastic-perfectly plastic behavior as $n \Longrightarrow \infty$ at which point the plastic moment of the joint is equal to the reference moment $M_{0}$ [56-61].

$$
\frac{\theta_{r}}{\theta_{0}}=\frac{M}{M_{0}}\left[1+\left(-\frac{M}{M_{0}}\right)^{n-1}\right] \quad \text { where } M_{0}=K_{i} \theta_{0}
$$

Ramberg \& Osgood's equation ( 2.6) was first used by Ang $\&$ Morris. Abolmaali et. al, who compared the momentrotation curve for flush end-plate connections generated by equation 2.6 with one using FEA, and found good results.

The nonlinear representation is used by Goldberg \& Richard; Richard \& Abbot and Attiogbe \& Morris which is represented by equation 2.7 and expressed by four parameters: reference bending moment $M_{0}$; rotational stiffness $K_{i}$; plastic rotational stiffness $K_{P}$ and a shape factor $n$ which is better than the Ramberg-Osgood equation as it allows positive, zero and negative plastic rotational stiffness $K_{P}$. Negative values are needful and fundamental when the connection fails due to local buckling.

$$
\frac{M}{M_{0}}=\frac{\left(1-\bar{K}_{P}\right) \frac{\theta_{r}}{\theta_{0}}}{\left[1+\left|\left(1-\bar{K}_{P}\right) \frac{\theta_{r}}{\theta_{0}}\right|^{n}\right]^{\frac{1}{n}}}+\bar{K}_{P} \frac{\theta_{r}}{\theta_{0}}
$$

$$
\text { where } \bar{K}_{P}=\frac{K_{P}}{K_{i}}
$$

Yee \& Melchers proposed an exponential model equation that also allows positive, zero and negative plastic rotational stiffness $K_{P}$. An important feature of this curve is that the slope of the curve at the origin is equal to the initial elastic stiffness of the connection.

$$
\frac{M}{M_{0}}=1-\exp \left[-\frac{\theta_{r}}{\theta_{0}}\left(1-\bar{K}_{P}+n^{\prime} \frac{\theta_{r}}{\theta_{0}}\right)\right]+\bar{K}_{P} \frac{\theta_{r}}{\theta_{0}}
$$

André Colson and Philippe Pilvin also proposed a nonlinear model for the representation of moment-rotation curve of the connections given respectively by equation 2.11 and 2.12 [62].

$$
\begin{gathered}
\frac{\theta_{r}}{\theta_{0}}=\frac{M}{M_{0}} \frac{1}{1-\left(\frac{M}{M_{0}}\right)^{n} \text { where } M_{0}=K_{i} \theta_{0}} \\
\frac{\theta_{r}}{\theta_{0}}=\frac{M}{M_{0}}\left[1+\frac{1}{2^{n}-1} \frac{\frac{M}{M_{0}}}{1-\frac{M}{M_{0}}}\right]
\end{gathered}
$$

\subsection{Cubic B-spline model}

A cubic polynomial model is used to fit segments of a curve. Between any two adjoining segments, the continuity of first and second derivatives of each segment of the curve is imposed. This method gives a good curve-fitting with test data but requires a large number of data in the curve-fitting process $[63,64]$. 


\subsection{Odd-power polynomial model}

Made to be able to give a close approach of the momentrotation behavior of connections without the need for testing, various mathematical models were proposed. Early models proposed included the curve-fitting of test data using regression analysis method. In 1975 John Frye and Glenn Morris proposed a method in which the moment rotation behavior is formulated in terms of the polynomial function. This model was developed based on a procedure by Sommer (1969). In this model, the $M-\theta$ behavior is represented by an odd-power polynomial. The method was outlined for expressing, in a nondimensional form, the moment-rotation characteristics for all connections of a given type. The rotation is expressed as a function of moment and other curve-fitting parameters. Curves are fitted to valid, effective, available and applicable experimental data of connections subjected to monotonic loadings. They used the method of least squares to determine the constants of the polynomial. The model represents the momentrotation relationship fairly well but the major drawback in the model is its prediction of negative tangent stiffness when the derivative of the polynomial function is taken within specific ranges. Since a polynomial function is characterized by peaks and valleys which is physically impossible. This is to say that the first derivative of this function which indicates connection stiffness, may be discontinuous and/or possibly negative [65]. The resulting $M-\theta$ relationship is expressed as follows:

$$
\theta_{r}=C_{1}(K M)+C_{2}(K M)^{3}+C_{3}(K M)^{5}
$$

Where:

$M$ and $\theta_{r}$ are the moment and rotation, respectively; $C_{1}, C_{2}$, and $C_{3}$ are curve-fitting constant parameters; $K$ is a standardized factor, parameter which is a function of important geometrical parameters such as the size of the connecting member and plate thickness. (a dimensionless factor whose value depends on the size parameters for the particular connection considered)

Equations were also included in the proposed model to predict the connection tangent $S_{c}$ stiffness, and the initial stiffness $S_{c}^{0}$, given by:

$$
\begin{gathered}
S_{c}=\frac{d M}{d \phi_{c}} \\
S_{c}=\frac{1}{C_{1} K+3 C_{2} K(K M)^{2}+5 C_{3} K(K M)^{4}} \\
S_{c}^{0}=\left.\frac{d M}{d \phi_{c}}\right|_{M}=0 \\
S_{c}^{0}=\frac{1}{C_{1} K}
\end{gathered}
$$

Curve fitting and standardization constants are listed in Table 1 in appendix.
- Type 1 = Single-web angle Connection

- Type 2 = Double-web angle Connection

- Type $3=$ Top-and seat-angle angle Connection

- Type $4=$ Top-and seat-angle angle with double web-angle Connection

- Type $5=$ End-plate connection with column stiffener

- Type $6=$ T-stud Connection

- Type $7=$ T-stud Connection

\subsection{Three-parameter power model}

A two-parameter power model has the form:

$$
\theta_{r}=a M^{b}
$$

Where $a$ and $b$ are two curve-fitting parameters under the conditions $a>0$ and $b>0$.

In 1975 Richard and Abbott proposed a three-parameter power model to represent the moment-rotation behavior of the connection under monotonic loading. The model is represented by the following expression:

$$
M=\frac{R_{k i} \theta_{r}}{\left[1+\left(\frac{\theta_{r}}{\theta_{0}}\right)^{n}\right]^{1 / n}}
$$

Where:

$R_{k i}$ is the initial connection stiffness; $n$ is the shape parameter; $\theta=M_{u} / R_{k i}$ is the reference plastic rotation; and $M_{u}$ is the ultimate moment capacity. Empirical equations for calculating the shape parameter $n$ are listed below in Table 2 in appendix and the resulting moment-rotation curves for different values of $n$ are shown in Figure 1 [66].

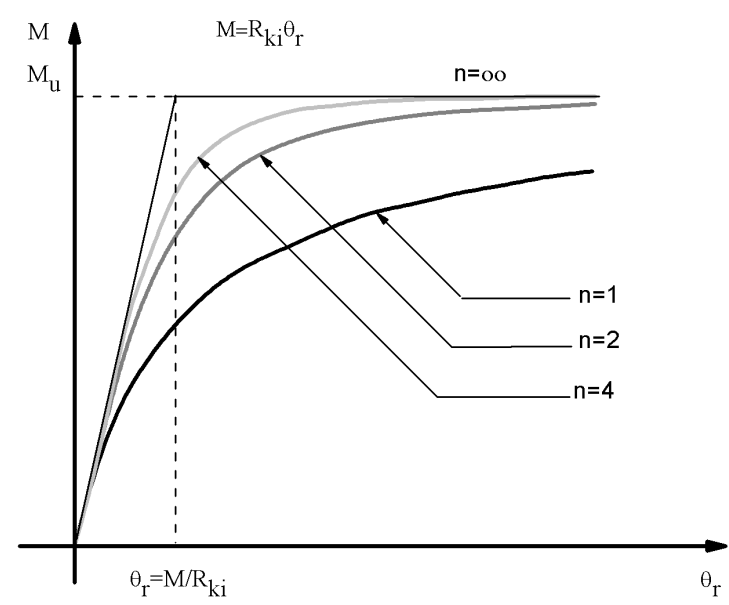

Figure 1. Three-parameter Power Model

As the connection tangent stiffness, $R_{k}$ and the relative rotation $\theta_{r}$ are determined directly without iterations from equation 
2.19, this model is viewed as an efficient means for conducting a second-order nonlinear structural analysis. However, contrariwise to the odd-power polynomial model in Section 2.6, the three-parameter power model requires a prior knowledge of the connection initial stiffness and ultimate moment capacity for a complete prediction of the moment-rotation response of the connection. Its prediction of the response, therefore, depends on two essential values that must be predicted by other means or models.

$$
R_{k}=\frac{d M}{d \theta_{r}}=\frac{R_{k i}}{\left[1+\left(\frac{\theta_{r}}{\theta_{0}}\right)^{n}\right]^{(n+1) / n}}
$$

In 1983, Colson and Louveau introduced again a threeparameter power function in the form of [67]:

$$
\theta_{r}=\frac{|M|}{K_{i}} \frac{1}{\left(1-\left|\frac{M}{M_{u}}\right|\right)^{n}}
$$

in 1987, Kishi and Chen proposed a similar power model in the form of:

$$
\theta_{r}=\frac{M}{K_{i}\left[1-\left(\frac{M}{M_{u}}\right)^{n}\right]^{1 / n}}
$$

In equations 2.21 and $2.22, K_{i}$ is the initial stiffness, $M_{u}$ is the ultimate moment and $n$ is a shape parameter. These two models may not be suitable for test curves that do not flatten out near the final loadings.

In order to give a relieve to the problem of Frye and Morris's model attached with the prediction of negative tangent connection stiffness when the derivative of the polynomial function is taken within specific ranges, Ang and Morris (1984) proposed the use of a standardized Ramberg-Osgood model to express the moment-rotation behavior of five typical types of connections including single web angle, double web-angle, header plate, top-and seat-angle, and the strap angle connections. The proposed model is in the subsequent equation:

$$
\frac{\theta}{\left(\theta_{r}\right)_{0}}=\left|\frac{K M}{(K M)_{0}}\right|\left[1+\left(\left|\frac{K M}{(K M)_{0}}\right|\right)^{n-1}\right]
$$

Where:

$\left(\theta_{r}\right)_{0},(K M)_{0}$, and $n$ are constants depending on the geometry and type of the connection. The advantage of the RambergOsgood function is that its derivative, the slope of the momentrotation $(M-\theta)$ curve, in contrary to the intrinsic oscillatory character of polynomials, does not oscillate.

\subsection{Exponential model}

In 1986, Lui and Chen proposed a method for analysing the behavior of flexibly-connected plane steel frames in the form of an exponential model expressed in the following formula:

$$
M=M_{0}+\sum_{j=1}^{n} C_{j}\left[1-\exp \left(-\frac{\left|\theta_{c}\right|}{2 j \alpha}\right)\right]+R_{k f}\left|\phi_{c}\right|
$$

Where:

$M$ is the connection moment, $M_{0}$ the starting value of the connection moment, $\left|\phi_{c}\right|$ the absolute value of the rotational deformation of the joint; $R_{k f}$ the strain-hardening stiffness of the connection, $\alpha$ a scaling factor, $n$ the number of terms considered, and $C_{j}$ the coefficients of curve-fitting. The tangent stiffness and the initial stiffness are given by equations 2.25 and 2.26 , respectively.

$$
S_{c}=\left.\frac{d M}{d \phi_{c}}\right|_{\left|\phi_{c}\right|=\left|\phi_{c}\right|}=\sum_{j=1}^{n} C_{j}\left[1-\exp \left(-\frac{\left|\theta_{c}\right|}{2 j \alpha}\right)\right]+R_{k f}
$$

$$
S_{c}^{0}=\sum_{j=1}^{n} \frac{C_{j}}{2 j \alpha}+D_{k} H\left[-\left|\theta_{k}\right|\right]_{k=1}
$$

The values of the curve fitting parameters were determined based on previous experimental data for four different types of connections are listed below in Table 3 in appendix.

The exponential model gives a good interpretation of the nonlinear behavior of connections but does not adequately portrait the connection behavior in case of a sudden and abrupt in the moment-rotation curve. Like the three-parameter power model of section 2.7, the exponential model demands a prior knowledge of various connection features such as the initial moment and the strain hardening stiffness. Yee and Melchers (1986) proposed a four-parameter exponential model:

$$
M=M_{P}\left[1-\exp \left|\frac{-\left(K_{i}-K_{P}+C \theta\right) \theta}{M_{P}}\right|\right]+K_{P} \theta
$$

Where $M_{P}$ is the plastic moment, $K_{i}$ is the initial stiffness, $K_{P}$ is the strain-hardening stiffness and $C$ is a constant controlling the slope of the curve.

\subsection{Modified Exponential Model}

In 1986, Kishi and Chen revised the exponential model of Chen-Lui, model to give room of accommodation to cases of abrupt change in moment-rotation curve. The moment-rotation behavior is then as described below by the subsequent equations $2.28[68,69]$.

$$
M=\sum_{j=1}^{n} C_{j}\left[1-\exp \left(-\frac{\left|\theta_{r}\right|}{2 j \alpha}\right)\right]+D
$$


Where:

$$
D=\sum_{k=1}^{n} D_{k}\left(\left|\theta_{r}\right|-\left|\theta_{k}\right|\right) H\left(\left|\theta_{r}\right|-\left|\theta_{k}\right|\right)
$$

Where:

$M_{0}$ is the initial connection moment which the curve is fitted, $D_{k}$ a constant curve-fitting parameter for the linear portion of the curve, $\theta_{k}$ starting rotation of $k$ th linear part of the curve from experimental, and $H[\theta]$ a Heaviside's step function.

The Heaviside step function is a mathematical function denoted as $\mathrm{H}(\mathrm{x})$, or sometimes theta(x) or $\mathrm{u}(\mathrm{x})$, Abramowitz et al. (1966), and also known as the unit step function. The term Heaviside step function and its symbol can represent either a piecewise constant function or a generalized function [70].

$$
\begin{array}{ll}
H[\theta]=1 & \text { for } \quad \theta \geq 0 \\
H[\theta]=0 & \text { for } \quad \theta<0
\end{array}
$$

\subsection{Simplified analytical models}

Furthermore, asides the curve fitting approach, simplified analytical models were also developed to predict the connection initial stiffness and ultimate moment. The models use equilibrium, compatibility, and material constitutive relations based on the notions of elastic structural analysis, to predict initial stiffness. Similarly, plastic analysis is used to predict ultimate moment.

In 1988, Kishi elaborated, from its geometrical and mechanical properties, the prediction of the initial stiffness and ultimate moment capacity of top-and seat-angle with double webangle connections using the subsequent equations:

$$
\begin{gathered}
K_{\phi}=\frac{3 E I_{t a} d_{1}^{2}}{g_{1}\left(g_{1}^{2}+0.78 t_{t a}^{2}\right.}+\frac{3 E I_{w a} d_{3}^{2}}{g_{3}\left(g_{3}^{2}+0.78 t_{w a}^{2}\right.} \\
I_{t a}=\frac{L_{t a} I_{t a}}{12} \text { and } I_{w a}=\frac{L_{w a} I_{w a}}{12} \\
M_{j, u}=\frac{2 V_{p u}+\frac{f_{y} t_{w a}}{2}}{6} L_{w a}^{2}
\end{gathered}
$$

Where:

$d_{i}$ and $g_{i}$ are geometrical parameters, $f_{y}$ the yield strength of the material, $E$ the elastic modulus, $I_{t a}$ and $I_{w a}$ the moment of inertias for the leg adjacent to the column face of the top angle and the web angle, respectively, $t_{t a}$ and $t_{w a}$ the thicknesses of the top angle and web angle, respectively, and $V_{p u}$ is obtained from the subsequent equation:

$$
\left(\frac{2 V_{p u}}{f_{y} t_{w a}}\right)+\frac{g_{c}-k_{a}}{t_{w a}}\left(\frac{2 V_{p u}}{f_{y} t_{w a}}\right)=1
$$

\section{Semi-rigid connections subjected to cyclic, dynamic and hysteresis load- ing}

In 1917, Wilson and Moore carried out the first studies on semirigid joints when they investigated the stiffness of riveted joints in steel structures. But studies into the relationship between the moment and rotation of semi-rigid joints and their overall effect on steel structures did not begin until the 1930s [71]. The study of dynamic behavior of semi-rigid frames seems to have begun with Lionberger and Weaver in 1969 followed by Suko and Adams in 1971. In these analyses the connection elasto-plastic behavior was modelled by equivalent springs [ $[17$, 72].

The behavior of joints under cyclic, dynamic and hysteresis loading is very significant for seismic performance evaluation of building structures in seismic zones. Because of their complexities in geometrical dimensions and shape, joints present complex nonlinear behavior. Researchers have focused on the development of predictive joint models based on test observations of various types of joints. There is a broad range of phenomenological models with varying degrees of complexity. It includes the Richard-Abbott model, the power model, the ChenLui exponential model and the bounding-line model. Although the phenomenological models have been widely used for structural design purposes, they should be carefully calibrated with test data for different joint design or type and loading scenarios [73-75].

The precision and reliability of a study depend strongly on the approximation of the model to the actual structure. Ductile steel frame with higher energy absorption capacity is generally more suitable for resistance against dynamic loads when compared to structures composed of other materials like Aluminum. The simulation of connection behavior under dynamic loads is one major factors for a precise steel structure model. The works of Popov on seismic moment connections for moment-resisting steel frames, Nade and Astaneh on dynamic behavior of flexible, semi-rigid and rigid steel frames and others have confirmed the hysteretic behavior of typical beam-to-column connections [76-78].

Resultantly, making an accurate numerical model ought to adopt this connection features. Other need for a precise dynamic study is on the nature of design for structures under dynamic loads. The concept of factor of safety for static analysis may not be strictly applicable to dynamic cases since resonance may occur when the disturbance frequency is close to the structure frequency. Connections are generally semi-rigid, the consideration of the influence of finite, nonlinear and hysteretic joint stiffness is essential for a precise study on the behavior 
of a steel structure. Semi-rigid jointed frames static study research has been extensive, possibly due to new classification of study methods for rigid and semi-rigid frames in several national codes. In spite of the extensive work on static analysis of semi-rigid steel frames, its dynamic analysis received relatively little attention till the 90's [76].

Tests by many researchers showed that the hysteretic loops under repeated and reversed loading are both stable and consistent. Static monotonic moment-rotation curve can then be used and extended to dynamic analysis [79-81].

The nonlinear moment-rotation behavior can be simulated by several types of models. They include the linear model, the bilinear model, the trilinear model, the polynomial model, the Ramberg-Osgood model, the Richard-Abbott model, and the exponential model. The linear, the bilinear and the polynomial models are simple to use but they may be too coarse and produce very drastic change in stiffness which is undesirable in terms of computational stability. The polynomial model is able to provide a better approximation, but could give undesired negative connection stiffness. The Ramberg-Osgood and the Richard-Abbott models require, respectively, three and four parameters and give a fairly good fit. The exponential model can provide an excellent fit and at least six parameters are used in modeling [6,58] \& [82-86].

Further, the exponential, the Ramberg-Osgood and the Richard-Abbott models can always give a positive derivative which is physically more acceptable. Thus, these three models are adopted for demonstration of the use of the present method of analysis and prediction of frame behavior. Under cyclic loads, the hysteretic loop as well as the instantaneous tangent connection stiffness of the moment-rotation $(M-\theta)$ curve will change in accordance with the current value of moment $\mathrm{M}$, the relative slip rotation $(\theta)$ and the increment/decrement of moment $(\Delta M)$ at a connection.

The algorithm described in [76] is applicable to any connection models, so many existing valuable laboratory data for static analysis can be employed and integrated into the computer code directly without an expensive and time-consuming curve-fitting procedure from one model to another [87]. The basic characteristics of the three models for a nonlinear connection under cyclic loading are summarized in [76], mainly: the exponential model, the Ramberg-Osgood model and the Richard-Abbott model.

Several other dynamic tests have been performed to investigate semi-rigid joints behavior and energy dissipation under cyclic loadings. Azizinamini \& Radziminski investigated Static and cyclic performance of semirigid steel beam-tocolumn connections. Nader \& Astaneh conducted a study on dynamic behavior of flexible, semirigid and rigid steel frames and Elnashai \& Elghazouli, the Seismic behavior of semi-rigid steel frames and Response of semirigid steel frames to cyclic and earthquake loads [88].

Several mathematic models for semi-rigid connections were proposed for representing momentrotation behavior under dynamic loading, both linear semi-rigid connection models and nonlinear semi-rigid connection models. In linear semi-rigid connection models, the stiffness of connections is assumed to be constant and stiffness matrix of a beamcolumn member is usually modified by using end-fixity factors. The advantage of these models were simple in formulation and implementation. However, these models do not consider the nonlinear behavior of semi-rigid connections, and furthermore they ignore the energy dissipation at connections. In nonlinear semi-rigid connection models, the stiffness of connections varies corresponding to different loading magnitudes and therefore these models can accurately capture the momentrotation relationship as well as the energy dissipation [73,74] \& [89-91].

In 1997, Lui \& Lopes reported the dynamic analysis and response of semirigid frames using stability functions. Two years later, Awkar \& Lui also reported the Seismic analysis and response of multistory semirigid frames using stability functions. Reports in which the momentrotation curves of semi-rigid joints were represented by the bilinear model, which do not accurately capture the nonlinear behavior of connections $[92,93]$.

As a knowledge-based modeling approach, numerous analyses on the application of neural networks (NN) in modeling the joints have been carry out [94-96].

In 2007, YUN et al. proposed a design-variable-based inelastic hysteretic model for the beamcolumn connections by combining NN-based cyclic material model with design information through simple mechanics or existing test database. As a new modeling concept of general mechanical components, the proposed model is not only limited to the beamcolumn connection but also can be extended to the other structural components and materials. The model was applied for steel beamColumn connections to demonstrate its potential application in earthquake engineering [97, 98].

In 2008, da Silva et al. worked on nonlinear dynamic analysis of steel portal frames with semi-rigid connections. They used ANSYS finite element software to represent the dynamic behavior of semi-rigid joints by employing approximate shape functions. Hence, if beamcolumn members are divided into a lot of elements, the second-order effects will be predicted more exactly so that it consumes computational time and computer resources intensively. The beamcolumn approach uses stability functions derived from the closed-form solutions of differential equation of beamcolumn element subjected to end forces. It is therefore able to evaluate exactly second-order effects by using only one element per member. This approach saves computer resources and reduces computational time [99].

In the above mentioned studies, the joints were modeled as single rotational springs attached at beam ends and the stiffness matrix of beam elements is modified to account for the stiffness of connections. The mentioned studies are limited to planar semi-rigid steel frames, but space frames were not analyzed.

In 2013, Nguyen and Kim present a simple effective numerical procedure based on the beamcolumn method for nonlinear elastic dynamic analysis of three-dimensional semi-rigid steel frames with semi-rigid connections. An independent zerolength connection element with six different translational and rotational springs connecting two different nodes with zero distance was developed. It was found efficient because modification of the beamcolumn stiffness matrix considering the semirigid connections is unneeded and the joint is set up to integrate any element types. The dynamic behavior of rotational springs 
is captured through the independent hardening model using KishiChen power model, the RichardAbbott four-parameter model, the ChenLui exponential model, and the RambergOsgood model. Rotational springs with constant stiffness were used to model linear semi-rigid connections. The second-order effects are considered by using stability functions employed by Kim and Thai for the nonlinear inelastic analysis of steel structures subjected to static and dynamic loadings. The Newmark numerical integration method combined with the NewtonRaphson iterative algorithm is adopted to solve the nonlinear motion equations at each incremental time step. The results of the second-order elastic dynamic response were compared with those of previous studies and commercial SAP2000 software to demonstrate the accuracy and computational efficiency [73, 74] \& [100-105].

\section{Bending-rotation relationship predic- tion formula}

\subsection{Prediction basic requirements}

For a good Aluminum hexagonal bolted joint (HBJ) modelling or behavior prediction, there are some basic requirements that need to be achieved: A nonlinear expression to depict the moment-rotation behavior of aluminum hexagonal bolted joint [106], semi-rigid connections should satisfy the subsequent requirements:

- The curve should pass through the origin coordinate $(0,0)$

- The slope of the curve at the origin coordinate $(0,0)$ should be equal to the initial elastic stiffness $K_{i}$ of the connection

- As $\theta$ becomes larger, the gradient of the curve (slope of the curve) should approach the strain-hardening stiffness, $K_{p}$

- For any value of $\theta$, the gradient of the expression represents the tangent stiffness of the connection

- The parameters in the expression of the model should have physical meaning

- The parameters in the expression of the model should be determined by a simple analytical procedure

- The expression of the model should be of relatively simple form

\subsection{Prediction basic assumptions}

For a good Aluminum hexagonal bolted joint modelling or behavior prediction, there are some basic assumptions that we need to form:

- The material is assumed to be linearly elastic perfectly plastic.

- Connection assemblage deformation is small.
- The deformation of the hollow rectangular member is negligible compared to the deformation of connections.

- Bolts tightening is effective, this produces a fastened, fixed and firm restraint. Deformation due to Slippage is negligible.

- The welding of the short hollow rectangular sub-member is good enough and effective to carry the member and the load, the three type of possible failure of a bolted joint.

- The failure model happens as the plastic collapse mechanisms formed in the connection assemble.

From the experimental studies the moment-rotation curves of Aluminum hexagonal bolted joint exhibit elastic-plastic hardening behavior and do not flatten out near the final state of loadings. The plastic failure mechanism is formed and the mechanism moment capacity is reached.

Based on the preceding requirements and assumptions, a simple quartic polynomial model is proposed in the current work to represent the moment-rotation behavior for Aluminum hexagonal bolted joint and verified with three other models, namely: the odd power polynomial model of Frye and Morris, three-parameter power model of Kishi and Chen and Fourparameter exponential model of Yee and Melchers.

A simple quartic polynomial function has the form:

$$
C_{1} X+C_{2} X^{2}+C_{3} X^{3}+C_{4} X^{4}+C_{5}=0
$$

The proposed formula for prediction of the behavior of Aluminum semi-rigid connections is expressed as followed:

$$
M=C_{1} \theta+C_{2} \theta^{2}+C_{3} \theta^{3}+C_{4} \theta^{4}+C_{5}
$$

Where $M$ is the moment of the connection, $\theta$ is the rotation of the connection. $C_{1}, C_{2}, C_{3}, C_{4}$ and $C_{5}$ constant values obtained by regression curve fitting.

\subsection{Assumptions and Prediction of Initial Stiff- ness}

To determine the initial stiffness of Aluminum HBJ connection, the following assumptions are made:

- The HBJ connection rotates about the center 0 of the Submember.

- The hollow rectangular sub-member connected to the central cylinder behaves in a linearly elastic manner and the hollow rectangular member connected to it behaves as a rigid body.

- The deformed shape of the sub-member is similar to that of the member.

- The bearing load is uniformly distributed over the submember. 
Based on the mentioned above assumptions and the deformation, the initial stiffness of Aluminum HBJ connections can be formulated from simple elastic beam theory $[107,108]$. It has the following form:

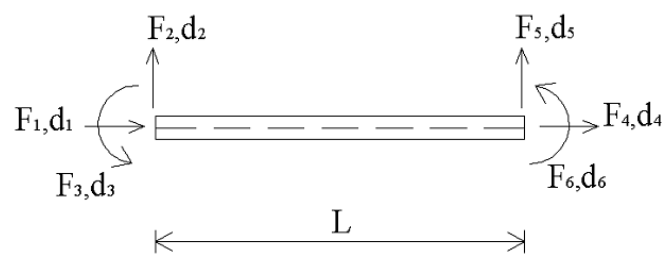

Figure 2. Beam member with end forces and displacements

Semi-rigid end connections of a beam can be represented by rotational springs as shown in Fig.4. $\theta_{r A}$ and $\theta_{r B}$ are the relative spring rotations of both ends and $K_{A}$ and $K_{B}$ are the corresponding spring stiffness expressed as:

$$
\begin{gathered}
K_{A}=\frac{M_{A}}{\theta_{r A}} \\
K_{B}=\frac{M_{B}}{\theta_{r B}}
\end{gathered}
$$

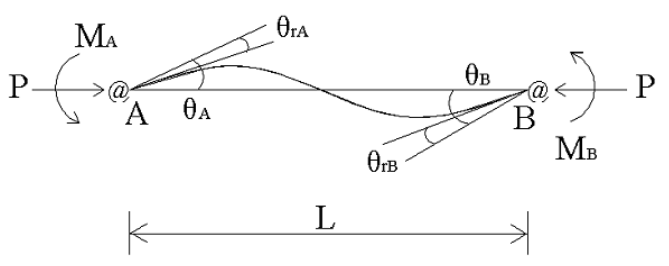

Figure 3. Beam member with rotational springs

The relationship between end-moments and end-rotations of a beam can be written by replacing the end-rotations $\theta_{A}$ and $\theta_{B}$ by $\left(\theta_{A}-\theta_{r A}\right)$ and $\left(\theta_{B}-\theta_{r B}\right)$ respectively, as follows:

$$
\begin{aligned}
& M_{A}=\frac{E I}{L}\left[4\left(\theta_{A}-\frac{M_{A}}{K_{A}}\right)+2\left(\theta_{B}-\frac{M_{B}}{K_{B}}\right)\right] \\
& M_{B}=\frac{E I}{L}\left[4\left(\theta_{B}-\frac{M_{B}}{K_{B}}\right)+2\left(\theta_{A}-\frac{M_{A}}{K_{A}}\right)\right]
\end{aligned}
$$

where $E$ is the Young modulus of elasticity and $I$ is mome of inertia of the member. Equations (4.5) and (4.6) can be e: pressed in the following form:

$$
\begin{aligned}
& M_{A}=\frac{E I}{L}\left(r_{i i} \theta_{A}+\left(r_{i j} \theta_{B}\right)\right. \\
& M_{B}=\frac{E I}{L}\left(r_{i j} \theta_{A}+\left(r_{j j} \theta_{B}\right)\right.
\end{aligned}
$$

$$
\begin{gathered}
r_{i i}=\frac{1}{K_{R}}\left(4+\frac{12 E I}{L K_{B}}\right) \\
r_{j j}=\frac{1}{K_{R}}\left(4+\frac{12 E I}{L K_{A}}\right) \\
r_{i j}=\frac{2}{K_{R}} \\
K_{R}=\left(1+\frac{4 E I}{L K_{A}}\right)\left(1+\frac{4 E I}{L K_{B}}\right)-\left(\frac{E I}{L}\right)^{2}\left(\frac{4}{K_{A} K_{B}}\right)^{2}
\end{gathered}
$$

Equations (4.7) and (4.8) can be converted to the following stiffness matrix of a semi-rigid beam member with 6 degrees of freedom in local coordinates (See appendix) [13].

Mechanism moment. For the proposed model, quartic polynomial model, the moment mechanism will be defined by bilinear approximation as illustrated in Figure 6, 7, 8, $9 \& 10$. The set $\left(M_{u}, \theta_{r u}\right)$ denotes the intersection point of the two straight lines which may be, approximately, taken as the test mechanism rotation and mechanism moment of the connection. The mechanism moment capacity of a connection is reached when an idealized elastic-plastic collapse mechanism is developed in the connection [27].

As seen in Figure 6, 7, 8, $9 \& 10$, the initial tangent stiffness is denoted by $K_{i}$. The secant stiffness corresponding to the plastic limit is denoted by $K_{u}$. Here in, the stiffness $\left(K_{i}\right)$ determined from experimental curves will be compared with those predicted by regression, Curve-fitting expresion. On the basis of the predicted initial stiffness $K_{i}$ and the mechanism moment $M_{u}$ together with appropriate range of parameters $C_{1}$, $C_{2}, C_{3}, C_{4}$ and $C_{5}$, a serie of the predicted moment-rotation curves can be determined and plotted to fit the appropriate test curves. Afterwards, the best curve-fitted parameter are chosen to represent each connection and can be now recommended for general use.

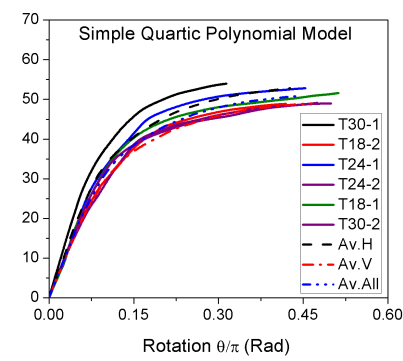

(a) Quartic polynomial model

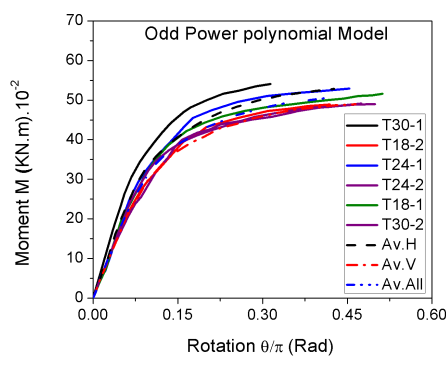

(b) odd power polynomial model
Figure 4. Quartic polynomial model \& odd power polynomial model in both direction (Fan \& Adeoti Model) \& (Frye \& Morris model)

With a close observation on Table 4, 5, 6, 7, 89 \& 10 (see appendix), it can be seen that the quartic polynomial model 


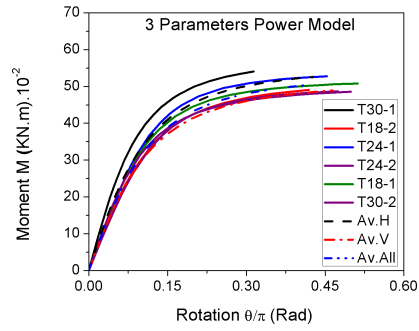

(a) 3 parameters power model

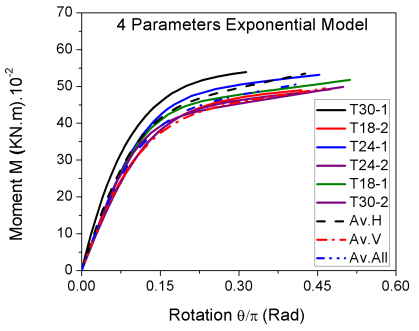

(b) 4 parameters exponential model

Figure 5. 3 parameters power model \& 4 parameters exponential model in both direction (Kishi \& Chen model) \& (Yee \& Melchers model)

and the odd power polynomial model are stable. For all the case considered the values of $C_{1}=1, C_{2}=2.5 \times 10^{-3}$, $C_{3}=10^{-4}, C_{4}=10^{-6}$, and $C_{5}=0$ in the quartic polynomial model in every case, $C_{1}=106.054, C_{2}=0, C_{3}=0, K=$ $9.43 \times 10^{-3}$ in the odd power polynomial model in every case. For all case considered the model expression did not change values of the parameters, one model is sufficient to represent every case considered which is not the case for the 3 parameters power model and 4 parameters exponential model. The values of the parameters changed for every case considered (see in appendix Table 4, 5, 6, 7, $89 \& 10$ for the values). Figure 4, 5 represent the graphs depicting all the models in every case.

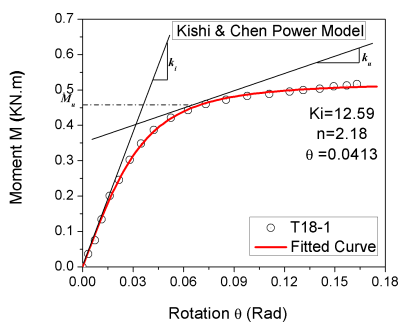

(a) Specimen T18-1 in the direction of the bolts

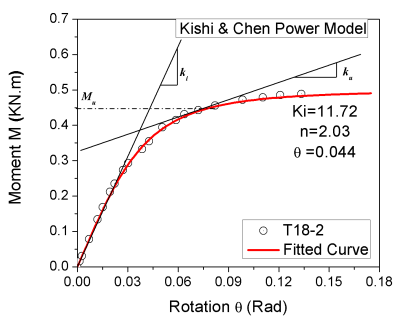

(b) T18-2 perpendicular to the direction of the bolts

Figure 6. Comparison of the moment-rotation curves obtained by the mathematical model and experiments T18-1 \& T18-2

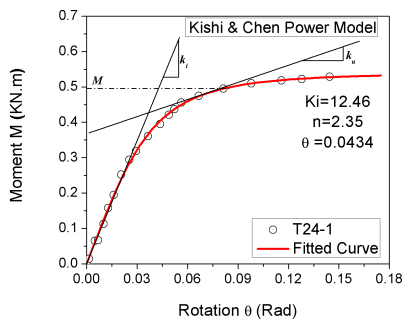

(a) Specimen T24-1 in the direction of the bolts

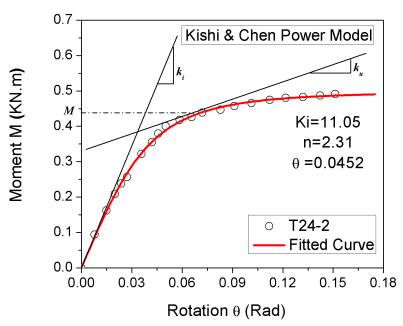

(b) T24-2 perpendicular to the direction of the bolts

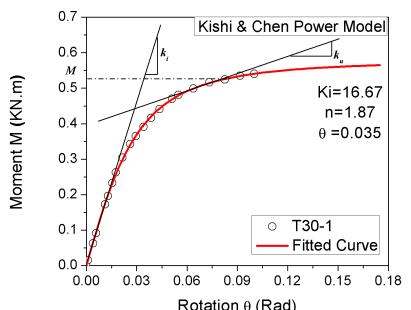

(a) Specimen T30-1 in the direction of the bolts

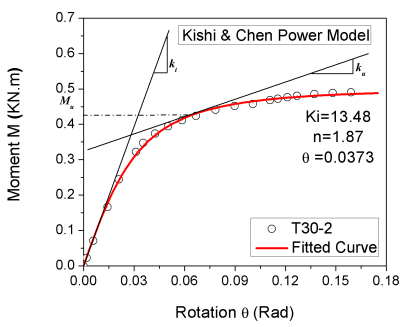

(b) T30-2 perpendicular to the direction of the bolts

Figure 8. Comparison of the moment-rotation curves obtained by the mathematical model and experiments T30-1 \& T30-2

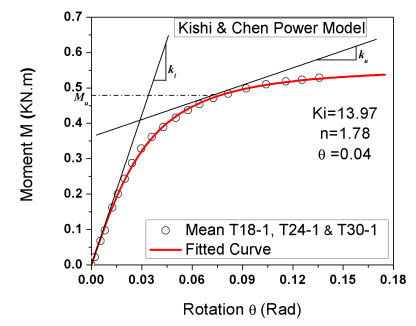

(a) Average of Specimen T18-1, T24-1 \& T30-1 in the direction of the bolts

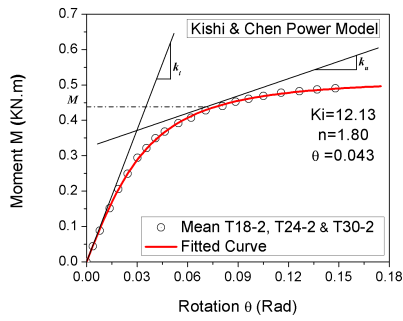

(b) Average of Specimen T18-2, T24-2 \& T30-2 perpendicular to the direction of the bolts

Figure 9. Comparison of the moment-rotation curves obtained by the mathematical model and experiments

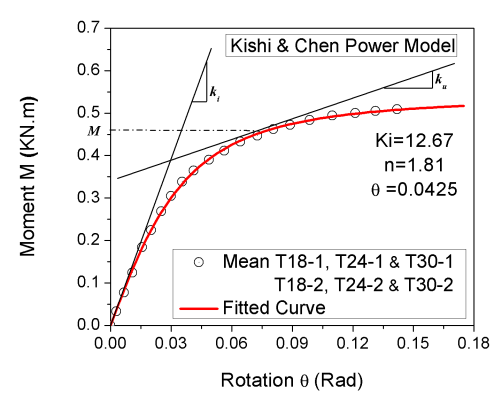

Figure 10. Comparison of the moment-rotation curves obtained by the mathematical model and experiments irrespective of the direction

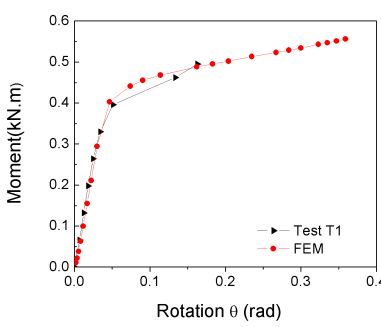

(a) Bending Moment-Rotation BPC Connection Specimen T1

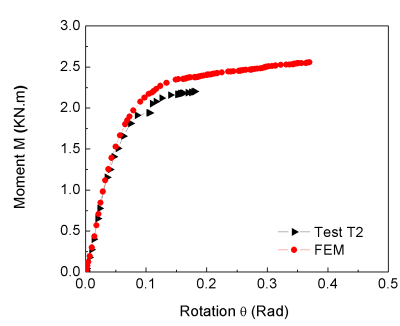

(b) Bending Moment-Rotation BPC Connection Specimen T2

Figure 7. Comparison of the moment-rotation curves obtained by the mathematical model and experiments T24-1 \& T24-2

Figure 11. Comparison of the bending moment-rotation curves for [109] connection specimen $\mathrm{T} 1 \& \mathrm{~T} 2$ 


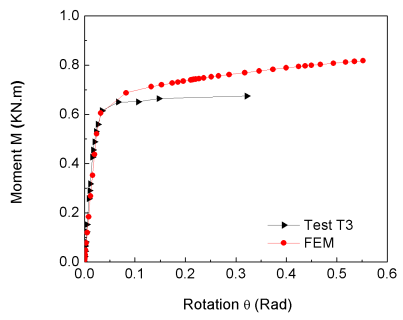

(a) Bending moment-rotation BPC connection specimen T3

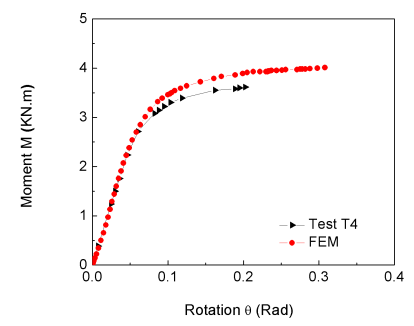

(b) Bending moment-rotation BPC connection specimen T4
Figure 12. Comparison of the bending moment-rotation curves for BPC connection specimen $\mathrm{T} 3$ \& $\mathrm{T} 4$

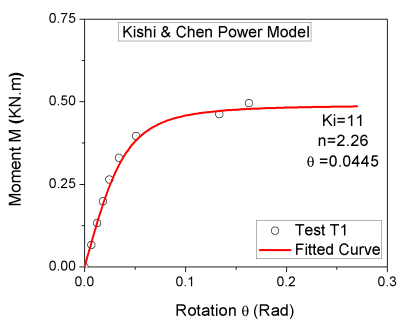

(a) BPC Connection Specimen T1

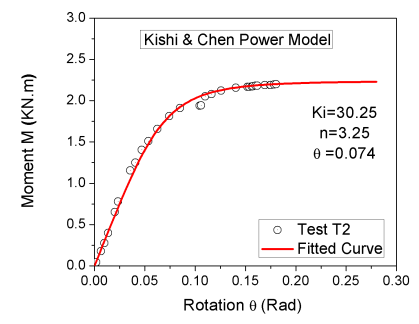

(b) BPC Connection Specimen T2
Figure 13. Comparison of the moment-rotation curves obtained by the mathematical model and experiments T1 \& T2

\section{Conclusions}

Space Structures connections systems were generally designed assuming that connections are ideally pinned or fully rigid. As a matter of fact, due to the finite stiffness of the connections, the true behavior of connection is semi-rigid, somewhere between these two extremes. Several research reports agree on the influence of the connection systems on the stability of Space Structures. Therefore, the behavior of connection systems should be considered in carrying out a structural analysis of any Space Structure, the rotational behavior of the joint should be considered. Up till here, the behavior of connections is portrayed by the moment-rotation curve in the analysis of the structure.

Several models, such as: mathematical, analytical, empirical, experimental, informational, mechanical and numerical can be used to obtain the moment-rotation curve. The most popular of these model is the mechanical model, of which the most used is the component method. With this method, it is possible to evaluate the rotational stiffness and moment capacity of semi-rigid joints when subjected to only pure bending but the method fails if there is the presence of an axial load.

In analyzing semi-rigid space structures, connection characteristics can be modeled with a mathematical model of the moment-rotation curve. According to the type of overall structural analysis required, one of several linear, bilinear, multilinear or nonlinear moment-rotation curve representations can be used. Accurate representation can be obtained using continuous nonlinear functions, but the multilinear representation is generally used for mechanical models.

Kishi \& Chen three parameter model, Yee \& Melchers four parameter exponential model used to represent the momentrotation behavior of the connections can portrait finely the behavior of the Aluminum bolted hexagonal connections and the bolted plate connection. Frye \& Morris model odd power polynomial model and the simple quartic polynomial model proposed are moment-rotation regression curve fitting models but can be used to fit very well the curve very well.

\section{Acknowledgments}

The authors gratefully acknowledge the financial support of this work by the National Natural Science Foundation of China: Major building and bridge structures and Earthquake Disaster Integration (91315301).

\section{References}

[1] D Nethercot. Methods of prediction of joint behaviour: Beam-to-column connections. Elsevier Applied Science, Structural Connections. Stability and Strength, pages 23-62, 1989.

[2] DA Nethercot and R Zandonini. Structural connection, stability and strength. chapter 2 . methods of prediction

Figure 14. Comparison of the moment-rotation curves obtained by the mathematical model and experiments T3 \& T4 
of joint behavior : Beam-to-column connection. Publication of: Jason Consultants SA, 1989.

[3] John Charles Rathbun. Elastic properties of riveted connections. American Society of Civil Engineers Transactions, 100(1):591-596, 1936.

[4] GR Monforton and Tien Hsing Wu. Matrix analysis of semi-rigid connected frames. Journal of the Structural Division (ASCE), 89(6):13-24, 1963.

[5] Edgar Lightfoot and Andrew P Le Messurier. Elastic analysis of frameworks with elastic connections. Journal of the Structural Division (ASCE), 100(6):12971309, 1974.

[6] M John Frye and Glenn A Morris. Analysis of flexibly connected steel frames. Canadian journal of civil engineering, 2(3):280-291, 1975.

[7] Arvind Vasant Goverdhan. A collection of experimental moment-rotation curves and evaluation of prediction equations for semi-rigid connections. $\mathrm{PhD}$ thesis, Vanderbilt University, 1983.

[8] KM Ang and GA Morris. Analysis of three-dimensional frames with flexible beam-column connections. Canadian Journal of Civil Engineering, 11(2):245-254, 1984.

[9] DA Nethercot. Steel beam-to-column connections-a review of test data and its applicability to the evaluation of joint behavior in the performance of steel frames. CIRIA, Construction Industry Research and Information Assoc., 23, 1985.

[10] N Kishi and WF Chen. Moment-rotation of semi-rigid connections. Structural Engineering Report, No. CESTR-87-29, School of Civil Engineering, Purdue University, West Lafayette, Indiana, September 1987.

[11] Norimitsu Kishi and Wai-Fah Chen. Data base of steel beam-to-column connections. Structural Engineering Area, School of Civil Engineering, Purdue University, 1986.

[12] Yoke Leong Yee and Robert E Melchers. Momentrotation curves for bolted connections. Journal of Structural Engineering, 112(3):615-635, March 1986.

[13] Wai-Fah Chen and Eric M Lui. Stability design of steel frames. CRC press, 1991.

[14] RM Richard and MK Elsalti. Prconn, moment-rotation curves for partially restrained connections. Users manual for program developed at The University of Arizona Department of Civil Engineering and Engineering Mechanics, 1991.

[15] Wai-Fah Chen and Shouji Toma. Advanced analysis of steel frames: theory, software, and applications. CRC press, 1994.
[16] Wai-Fah Chen, Norimitsu Kishi, and Masato Komuro. Semi-rigid connections handbook. J. Ross Publishing, 2011.

[17] Steve R Lionberger and William Weaver. Dynamic response of frames with nonrigid connectors. Journal of the Engineering Mechanics Division ASCE, 95(1):95$114,1969$.

[18] Karl M Romstad and Chittoor V Subramanian. Analysis of frames with partial connection rigidity. Journal of the Structural Division, 96(11):2283-2300, 1970.

[19] Piotr D Moncarz and Kurt H Gerstl. Steel frames with nonlinear connections. Journal of the Structural Division, 107(8):1427-1441, 1981.

[20] Robert F Lorenz, Wai-Fah Chen, Committee Connections Council on Tall Buildings, and Urban Habitat. Semi-rigid connections in steel frames. McGraw-Hill, 1993.

[21] FGA Al-Bermani, B Li, K Zhu, and S Kitipornchai. Cyclic and seismic response of flexibly jointed frames. Engineering Structures, 16(4):249-255, 1994.

[22] SW Jones, PA Kirby, and DA Nethercot. Effect of semirigid connections on steel column strength. Journal of Constructional Steel Research, 1(1):38-46, 1980.

[23] Stephen Wynford Jones, PA Kirby, and DA Nethercort. The analysis of frames with semi-rigid connectionsa state-of-the-art report. Journal of Constructional Steel Research, 3(2):2-13, 1983.

[24] EM Lui and Wai-Fah Chen. Analysis and behaviour of flexibly-jointed frames. Engineering Structures, 8(2):107-118, 1986.

[25] Norimitsu Kishi and Wai-Fah Chen. On steel connection data bank at purdue university. Materials and Member Behavior, pages 89-106, 1987.

[26] Wai-Fah Chen, Yoshiaki Goto, and JY Richard Liew. Stability design of semi-rigid frames, volume 1. John Wiley \& Sons, 1996.

[27] Fu-Hsiang Wu and Wai-Fah Chen. A design model for semi-rigid connections. Engineering Structures, 12(2):88-97, 1990.

[28] André Colson. Theoretical modeling of semirigid connections behavior. Journal of constructional steel research, 19(3):213-224, 1991.

[29] Natarajan Krishnamurthy, Louie K Avery, Paul K Jeffrey, and Horng-Te Huang. Analytical $\backslash$ im- $\theta$ curves for end-plate connections. Journal of the Structural Division, 105(1):133-145, 1979.

[30] N Krishnamurthy. Modelling and prediction of steel bolted connection behavior. Computers \& Structures, 11(1):75-82, 1980. 
[31] AR Kukreti, TM Murray, and A Abolmaali. End-plate connection moment-rotation relationship. Journal of Constructional Steel Research, 8:137-157, 1987.

[32] MR Bahaari and AN Sherbourne. Computer modelling of an extended end-plate bolted connection. Computers \& structures, 52(5):879-893, 1994.

[33] Archibald N Sherbourne and Mohammed R Bahaari. 3d simulation of end-plate bolted connections. Journal of Structural Engineering, 120(11):31223136, November 1994.

[34] KM Abdalla and GE Stavroulakis. Backpropagation neural network model for semi-rigid steel connections. Computer-Aided Civil and Infrastructure Engineering, 10(2):77-87, 1995.

[35] M R Chenaghlou and H Nooshin. Estimation of semirigidity of connectionsin space structures using neural network. In Proceedings of Asia-Pacific Conference on Shell and Spatial Structures, pages 238-246, Beijing, China, 1996.

[36] D Anderson, EL Hines, SJ Arthur, and EL Eiap. Application of artificial neural networks to the prediction of minor axis steel connections. Computers \& Structures, 63(4):685-692, May 1997.

[37] CW Wong and SWH Mak. System identification of semi-rigid connections in steel frame structures. In Proceedings of SPIE - The International Society for Optical Engineering, pages 267-267. SEM Society for Experimental Mechanic INC, 1993.

[38] Y Ren and CF Beards. Identification of joint properties of a structure using frf data. Journal of Sound and Vibration, 186(4):567-587, October 1995.

[39] Egor P Popov and Bruce R Pinkney. Cyclic yield reversal in steel building connections. Journal of the Structural Division, ASCE, 95(9):327-353, 1969.

[40] FM Mazzolani. Mathematical model for semi-rigid joints under cyclic loads. Connections in Steel Structurs: Behaviour, Strength and Design, Elsevier Applied Science Publishers, London, pages 112-120, 1988.

[41] Goto Yoshiaki, Suzuki Satsuki, and Chen Wai-Fah. Analysis of critical behavior of semi-rigid frames with or without load history in connections. International Journal of Solids and Structures, 27(4):467-483, 1991.

[42] F M Mazzolani and S Mazzolani. The new space structure of malpensa 2000: Test and design. In Proceedings of International Symposium on Spatial Structures: Heritage, Present and Future, pages 707-714, Milano, Italia, 1995.

[43] Ciro Faella, Vincenzo Piluso, and Gianvittorio Rizzano. Structural steel semirigid connections: theory, design, and software, volume 21. CRC press, 1999.
[44] European Committee for Standardisation (CEN). Eurocode 3: Design of steel structures, part 1-8: Design of joints. Brussels: European Committee for Standardization, 2005.

[45] C Batho. Investigations on beam and stanchion connections, 1st report, steel structures research committee, vol. 1-2dept. of scientific and industrial research. HMSO, London, Vol. I-2:61-137, 1931.

[46] C Batho and HC Rowan. Investigations on beam and stanchion connections. Second report of the Steel Structures Research Committee, pages 61-137, 1934.

[47] C. Bathe and S. D. Lash. Further investigations on beam and stanchion connections encased in concrete, together with lab. investigation on a full scale steel frame, final report, steel structures research committee, dept. of scientific and industrial research. HMSO, London, pages 276-363, 1936.

[48] RE Melchers and D Kaur. Behaviour of frames with flexible joints. In Proc 8th Australian conf mech of structural materials, pages 271-275, 1982.

[49] Hironori Sugimoto and Wai F Chen. Small end restraint effects on strength of h-columns. Journal of the Structural Division, 108(3):661-681, 1982.

[50] EM Lui and WF Chen. Strength of h-columns with small end restraints. Structural Engineer, 61:17-26, 1983.

[51] Sriramulu Vinnakota. Planar strength of restrained beam columns. Journal of the Structural Division, 108(11):2496-2516, 1982.

[52] Zia Razzaq. End restraint effect on steel column strength. Journal of Structural Engineering, 109(2):314-334, 1983.

[53] C Poggi and R Zandonini. Behaviour and strength of steel frames with semi-rigid connections. In Connection Flexibility and Steel Frames, pages 57-76. ASCE, 1985.

[54] Akbar Pirmoz, Amir Seyed Khoei, Ebrahim Mohammadrezapour, and Amir Saedi Daryan. Momentrotation behavior of bolted top-seat angle connections. Journal of Constructional Steel Research, 65(4):973984, April 2009.

[55] AA Del Savio, DA Nethercot, PCGS Vellasco, SAL Andrade, and LF Martha. Generalised component-based model for beam-to-column connections including axial versus moment interaction. Journal of Constructional Steel Research, 65(8):1876-1895, 2009.

[56] Walter Ramberg and William R Osgood. Description of stress-strain curves by three parameters. National advisory committee for aeronautics, 1943. 
[57] John E Goldberg and Ralph H Richard. Analysis of non-linear structures. Journal of the Structural Division, 89(4):333-352, 1963.

[58] Ralph M Richard and Barry J Abbott. Versatile elasticplastic stress-strain formula. Journal of the Engineering Mechanics Division, 101(4):511-515, 1975.

[59] Emmanuel Attiogbe and Glenn Morris. Momentrotation functions for steel connections. Journal of Structural Engineering, 117(6):1703-1718, June 1991.

[60] Ali Abolmaali, John H Matthys, Mohammed Farooqi, and Yeol Choi. Development of moment-rotation model equations for flush end-plate connections. Journal of Constructional Steel Research, 61(12):1595-1612, 2005.

[61] Concepción Díaz, Pascual Martí, Mariano Victoria, and Osvaldo M Querin. Review on the modelling of joint behaviour in steel frames. Journal of Constructional Steel Research, 67(5):741-758, May 2011.

[62] Philippe Pilvin. Modélisation du comportement des assemblages de structures à barres. $\mathrm{PhD}$ thesis, France: Université de Paris 6, 1983.

[63] Maurice G Cox. The numerical evaluation of b-splines. IMA Journal of Applied Mathematics, 10(2):134-149, 1972.

[64] SW Jones, PA Kirby, and DA Nethercot. Modelling of semi-rigid connection behaviour and its influence on steel column behaviour. Joints in structural steelwork, 9, 1981 .

[65] Werner Hans Sommer. Behaviour of Welded Header Plate Conections. $\mathrm{PhD}$ thesis, University of Toronto, at Toronto, Canada, 1969. Thesis presented to University of Toronto, at Toronto, Canada, in partial fulfillment of the requirements for the degree of Master of Applied Science.

[66] Natarajan Krishnamurthy, Louie K Avery, Paul K Jeffrey, and Horng-Te Huang. Analytical $\backslash$ im- $\theta$ curves for end-plate connections. Journal of the Structural Division, 105(1):133-145, 1979.

[67] A Colson and JM Louveau. Connections incidence on the inelastic behavior of steel structures. In Euromech Colloquium, volume 174, 1983.

[68] N Kishi and WF Chen. Data base of steel beam-tocolumn connections. West Lafayette, Purdue University, $1986 a$.

[69] N Kishi and WF Chen. Data base of steel beam-tocolumn connections. West Lafayette, Purdue University, $1986 b$.

[70] Milton Abramowitz, Irene A Stegun, et al. Handbook of mathematical functions. Applied mathematics series, 55:62, 1966.
[71] Wilbur M Wilson and Herbert Fisher Moore. Tests to determine the rigidity of riveted joints of steel structures. Bulletin/University of Illinois, Engineering Experiment Station; no. 104, 1917.

[72] Suko M and Adams PF. Dynamic analysis of multibay multistory frames. Journal of the Structural Division, ASCE, 97:251933, 1971.

[73] Richard RM and Abbott BJ. Versatile elastic-plastic stressstrain formula. Journal of Engineering Mechanics Division ASCE, 101:511-5, 1975.

[74] Lui EM and Chen WF. Steel frame analysis with flexible joints. Journal of Constructional Steel Research, 8:161202, 1987.

[75] Albermani FGA, Li B, Zhu K, and Kitipornchai S. Cyclic and seismic response of flexibly jointed frames. Engineering Structures, 16:249255, 1994.

[76] Chui PPT and Chan SL. Transient response of momentresistant steel frames with flexible and hysteretic joints. Journal of Constructional Steel Research, 39:221-43, 1996.

[77] E. P. Popov. Seismic moment connections for momentresisting steel frames. Report no. ucb/eerc-83/02, earthquake engineering research center, College of EngiLneering, University of California, Berkeley, CA, January,, 1983.

[78] Nader MN and Astaneh A. Dynamic behaviour of flexible, semi-rigid and rigid steel frames. Journal of Constructional Steel Research, 18:179-92, 1991.

[79] V. T. Vedero and E. P. Popov. Beam-column subassemblages under repeated loading. Journal of the Structural Division, ASCE, 98(5):1137-1159, 1972.

[80] K. C. Tsai and E. P. Popov. Cyclic behavior of end-plate moment connections. Journal of the Structural Division, ASCE, 116(11):2917-2930, 1990.

[81] Atorod Azizinamini and James B Radziminski. Static and cyclic performance of semirigid steel beam-tocolumn connections. Journal of Structural Engineering, 115(12):2979-2999, December 1989.

[82] K. H. Gerstle. Effect of connections on frames. Journal of Constructional Steel Research, 10:241-267, 1988.

[83] Walter Ramberg and William R Osgood. Description of stress-strain curves by three parameters. National advisory committee for aeronautics, 1943.

[84] L. Gao and A. Haldar. Nonlinear seismic analysis of space structures with partially restrained connections. Microcomputers in Civil Engineering, 10:27-37, 1995.

[85] E. M. Lui and W. F. Chen. Behavior of braced and unbraced semi-rigid frames. International Journal of Solids and Structures, 24(9):893-913, 1988. 
[86] K. S. Sivakumaran. Seismic response of multi-storey steel buildings with flexible connections. Engineering Structures, 10:239-248, 1988.

[87] Wai-Fah Chen and N Kishi. Semirigid steel beam-tocolumn connections: Data base and modeling. Journal of Structural Engineering, 115(1):105-119, January 1989.

[88] Elnashai AS, Elghazouli AY, and Denesh-Ashtiani FA. Response of semirigid steel frames to cyclic and earthquake loads. Journal of Structural Engineering, 124:857-67, 1998.

[89] Yu CH and Shanmugam NE. Stability of semi-rigid space frames. Computer \& Structures, 28:85-91, 1988.

[90] Xu L. The buckling loads of unbraced pr frames under non-proportional loading. Journal of constructional steel research, 58:443-65, 2002.

[91] Chen WF and Kishi N. Semirigid steel beam-to-column connections - data-base and modeling. Journal of Structural Engineering ASCE, 115:105-19, 1989.

[92] Lui EM and Lopes A. Dynamic analysis and response of semirigid frames. Engineering Structures, 19:64454, 1997.

[93] Awkar JC and Lui EM. Seismic analysis and response of multistory semirigid frames. Engineering Structures, 21:425-41, 1999.

[94] Anderson D, Hines EL, Arthur SJ, and Eiap EL. Application of artificial neural networks to the prediction of minor axis steel connections. Computers \& Structures, 63(4):68592, 1997.

[95] Sakla SSS. Neural network modeling of the loadcarrying capacity of eccentrically-loaded single-angle struts. Journal of Constructional Steel Research, 60:965-987, 2004.

[96] FEMA-355D. State of the art report on connection performance. FEMA-355D, SAC Joint Venture, 2000.

[97] G. J. YUN, J. GHABOUSSI, and A. S. ELNASHAI. A design-variable-based inelastic hysteretic model for beam-column connections. Earthquake Engineering and Structural Dynamics, 37:535555, 2007.

[98] Yun GJ, Ghaboussi J, and Elnashai AS. A new neural network-based model for hysteretic behavior of materials. International Journal for Numerical Methods in Engineering, 73(4):44769, 2008.

[99] da Silva JGS, de Lima LRO, Vellasco PCG da S, de Andrade SAL, and de Castro RA. Nonlinear dynamic analysis of steel portal frames with semi-rigid connections. Engineering Structures, 30:2566-79, 2008.
[100] Phu-Cuong Nguyen and Seung-Eock Kim. Nonlinear elastic dynamic analysis of space steel frames with semi-rigid connections. Journal of Constructional Steel Research, 84:72-81, May 2013.

[101] Walter Ramberg and William R Osgood. Description of stress-strain curves by three parameters. Tech. Note No. 902, National Advisory Committee for Aeronautics, Washington, D. C., 1943.

[102] Kim SE and Thai HT. Nonlinear inelastic dynamic analysis of suspension bridges. Engineering Structures, 32:3845-56, 2010.

[103] Thai HT and Kim SE. Practical advanced analysis software for nonlinear inelastic analysis of space steel structures. Advance Engineering Software, 40:786-97, 2009.

[104] Thai HT and Kim SE. Practical advanced analysis software for nonlinear inelastic dynamic analysis of steel structures. Journal of Constructional Steel Research, 67:453-61, 2011.

[105] SAP2000v15.0. Linear and nonlinear static and dynamic analysis and design of three-dimensional structures. Berkeley, California, USA, 2011.

[106] Guy Oyeniran Adeoti, Feng Fan, MA Huihuan, and Shizhao Shen. Investigation of aluminium bolted joint (hbj) system behavior. Thin-Walled Structures, 144:106100, November 2019.

[107] JM Gere and SP Timoshenko. Mechanics of materials (2nd edn.) wadsworth. Inc, Belmont, California, pages 623-666, 1984.

[108] Fu-Hsiang Wu. Semi-rigid connections in steel frames, Ph.D. Dissertation, School of Civil Engineering. PhD thesis, Purdue University, West Lafayette. IN, December 1988.

[109] Hui-Huan Ma, Ali Mohamed Issa, Feng Fan, and Guy Oyeniran Adeoti. An experimental and numerical study of a semi-rigid bolted-plate connections (bpc). Thin-Walled Structures, 88:82-89, March 2015.

[110] Balaur S Dhillon and James W O'Malley III. Interactive design of semirigid steel frames. Journal of Structural Engineering, 125(5):556-564, May 1999.

\section{LIST OF FIGURES}

Figure 1: Three-parameter power model

Figure 2: Beam member with end forces and displacements

Figure 3: Beam member with rotational springs

Figure 4: Quartic polynomial model \& odd power polynomial model in both direction (Fan \& Adeoti model) \& (Frye \& Morris model) 
Figure 5: 3 parameters power model \& 4 parameters exponential model in both direction (Kishi \& Chen model) \& (Yee \& Melchers model)

Figure 6: Comparison of the moment-rotation curves obtained by the mathematical model and experiments T18-1 \& T18-2

Figure 7: Comparison of the moment-rotation curves obtained by the mathematical model and experiments T24-1 \& T24-2

Figure 8: Comparison of the moment-rotation curves obtained by the mathematical model and experiments T30-1 \& T30-2

Figure 9: Comparison of the moment-rotation curves obtained by the mathematical model and experiments

Figure 10: Comparison of the moment-rotation curves obtained by the mathematical model and experiments irrespective of the direction

Figure 11: Comparison of the bending moment-rotation curves for BPC connection specimen $\mathrm{T} 1 \& \mathrm{~T} 2$

Figure 12: Comparison of the bending moment-rotation curves for BPC connection specimen T3 \& T4

Figure 13: Comparison of the moment-rotation curves obtained by the mathematical model and experiments T1 \& T2

Figure 14: Comparison of the moment-rotation curves obtained by the mathematical model and experiments T3 \& T4

\section{LIST OF TABLES}

Table 1: Curve-fitting and standardization constants for FryeMorris polynomial model

Table 2: Empirical equations for shape parameters n (Richard and Abbott 1975)

Table 3: Connection parameters of the Chen-Lui exponential model (Chen 2000)

Table 4: Parameters values for various models for Aluminum connection T18-1 \& T18-2

Table 5: Parameters values for various models for Aluminum connection T24-1 \& T24-2

Table 6: Parameters values for various models for Aluminum connection T30-1 \& T30-2

Table 7: Parameters values for various models for Aluminum connection Test average Values

Table 8: Parameters values for various models for Aluminum connection test average values irrespective of the direction of the bolts
Table 9: Parameters values for various models for Aluminum connection $\mathrm{T} 1 \& \mathrm{~T} 2$

Table 10: Parameters values for various models for Aluminum connection T3 \& T4 


\section{APPENDIX}

Table 1. Curve-fitting and standardization constants for Frye-Morris polynomial model

\begin{tabular}{|c|c|c|}
\hline Connection types & Curve-fitting constants & Standardization constants \\
\hline Type 1 & $\begin{array}{c}C_{1}=4.28 \times 10^{-} 3 \\
C_{2}=1.45 \times 10^{-} 9 \\
C_{3}=1.51 \times 10^{-} 16\end{array}$ & $K=d^{-2.4} \cdot t^{-1.18} \cdot g^{0.15}$ \\
\hline Type 2 & $\begin{array}{l}C_{1}=3.66 \times 10^{-} 4 \\
C_{2}=1.15 \times 10^{-} 6 \\
C_{3}=4.57 \times 10^{-} 8\end{array}$ & $K=d^{-2.4} \cdot t^{-1.18} \cdot g^{0.15}$ \\
\hline Type 3 & $\begin{array}{l}C_{1}=8.46 \times 10^{-} 4 \\
C_{2}=1.01 \times 10^{-} 4 \\
C_{3}=1.24 \times 10^{-} 8\end{array}$ & $K=d^{-1.5} \cdot t^{-0.5} \cdot l^{-0.07} \cdot d_{b}^{-1.1}$ \\
\hline Type 4 & $\begin{array}{c}C_{1}=2.23 \times 10^{-} 5 \\
C_{2}=1.85 \times 10^{-} 8 \\
C_{3}=3.19 \times 10^{-} 12\end{array}$ & $K=d^{-1.287} \cdot t^{-1.128} \cdot t^{-0.415} \cdot l^{-0.694} \cdot\left(g-\frac{d_{b}}{2}\right)^{1.350}$ \\
\hline Type 5 & $\begin{array}{l}C_{1}=1.79 \times 10^{-} 3 \\
C_{2}=1.76 \times 10^{-} 4 \\
C_{3}=2.04 \times 10^{-} 4\end{array}$ & $K=d^{-2.4} \cdot t^{-0.6}$ \\
\hline Type 6 & $\begin{array}{c}C_{1}=2.1 \times 10^{-} 4 \\
C_{2}=6.2 \times 10^{-} 6 \\
C_{3}=-7.6 \times 10^{-} 9\end{array}$ & $K=d^{-1.5} \cdot t^{-0.5} \cdot f^{-1.1} \cdot l^{-0.7}$ \\
\hline Type 7 & $\begin{array}{l}C_{1}=5.1 \times 10^{-} 5 \\
C_{2}=6.2 \times 10^{-} 10 \\
C_{3}=2.4 \times 10^{-} 13\end{array}$ & $K=t^{-1.6} \cdot g^{1.6} \cdot d^{-2.3} \cdot w^{0.5}$ \\
\hline
\end{tabular}

Table 2. Empirical equations for shape parameters n (Richard and Abbott 1975)

\begin{tabular}{cccc}
\hline Type No. & Connection types & \multicolumn{2}{c}{$n$} \\
\hline I & Single web-angle connection & $0.520 \log _{10} \theta_{0}+2.291$ & $\ldots \log _{10} \theta_{0}>-3.073$ \\
& & 0.695 & $<-3.073$ \\
II & Double web-angle connection & $1.322 \log _{10} \theta_{0}+3.952$ & $\ldots \log _{10} \theta_{0}>-2.582$ \\
& & 0.573 & $<-2.582$ \\
III & Top- and seat-angle connection & $1.398 \log _{10} \theta_{0}+4.631$ & $\ldots \log _{10} \theta_{0}>-2.721$ \\
& (without double web-angle) & 0.827 & $<-2.721$ \\
IV & Top- and seat-angle connection & $2.003 \log _{10} \theta_{0}+6.070$ & $\ldots \log _{10} \theta_{0}>-2.880$ \\
& (with double web-angle) & 0.302 & $<-2.880$ \\
\hline
\end{tabular}


Table 3. Connection parameters of the Chen-Lui exponential model (Chen 2000)

\begin{tabular}{ccccc}
\hline \multicolumn{5}{c}{ Connection type (kips-in) } \\
\hline & $\begin{array}{c}\mathrm{A} \\
\text { Single web angle }\end{array}$ & $\begin{array}{c}\text { Top-and seat-angle } \\
\text { with double web-angle }\end{array}$ & $\begin{array}{c}\text { Flush-end plate } \\
\text { Extended end plate }\end{array}$ & E \\
\hline$M_{0}$ & 0 & 0 & 0 & 0 \\
$R_{k f}$ & $0.47104 \times 10^{2}$ & $0.443169 \times 10^{3}$ & $0.96415 \times 10^{3}$ & $0.41193 \times 10^{3}$ \\
$\alpha$ & $-0.51167 \times 10^{-3}$ & $0.31425 \times 10^{-3}$ & $0.31783 \times 10^{-3}$ & $0.67083 \times 10^{-3}$ \\
$C_{1}$ & $-0.43300 \times 10^{2}$ & $-0.34515 \times 10^{3}$ & $-0.25038 \times 10^{3}$ & $-0.67824 \times 10^{3}$ \\
$C_{2}$ & $0.12139 \times 10^{4}$ & $0.52345 \times 10^{4}$ & $0.50736 \times 10^{4}$ & $0.27084 \times 10^{4}$ \\
$C_{3}$ & $-0.58583 \times 10^{4}$ & $-0.26762 \times 10^{5}$ & $-0.30396 \times 10^{5}$ & $-0.21389 \times 10^{5}$ \\
$C_{4}$ & $0.12971 \times 10^{5}$ & $0.61920 \times 10^{5}$ & $0.75338 \times 10^{5}$ & $0.78563 \times 10^{5}$ \\
$C_{5}$ & $-0.13374 \times 10^{5}$ & $-0.65114 \times 10^{5}$ & $-0.82873 \times 10^{5}$ & $-0.99740 \times 10^{5}$ \\
$C_{6}$ & $0.52224 \times 10^{4}$ & $0.25506 \times 10^{5}$ & $0.33927 \times 10^{5}$ & $0.43042 \times 10^{5}$ \\
\hline
\end{tabular}

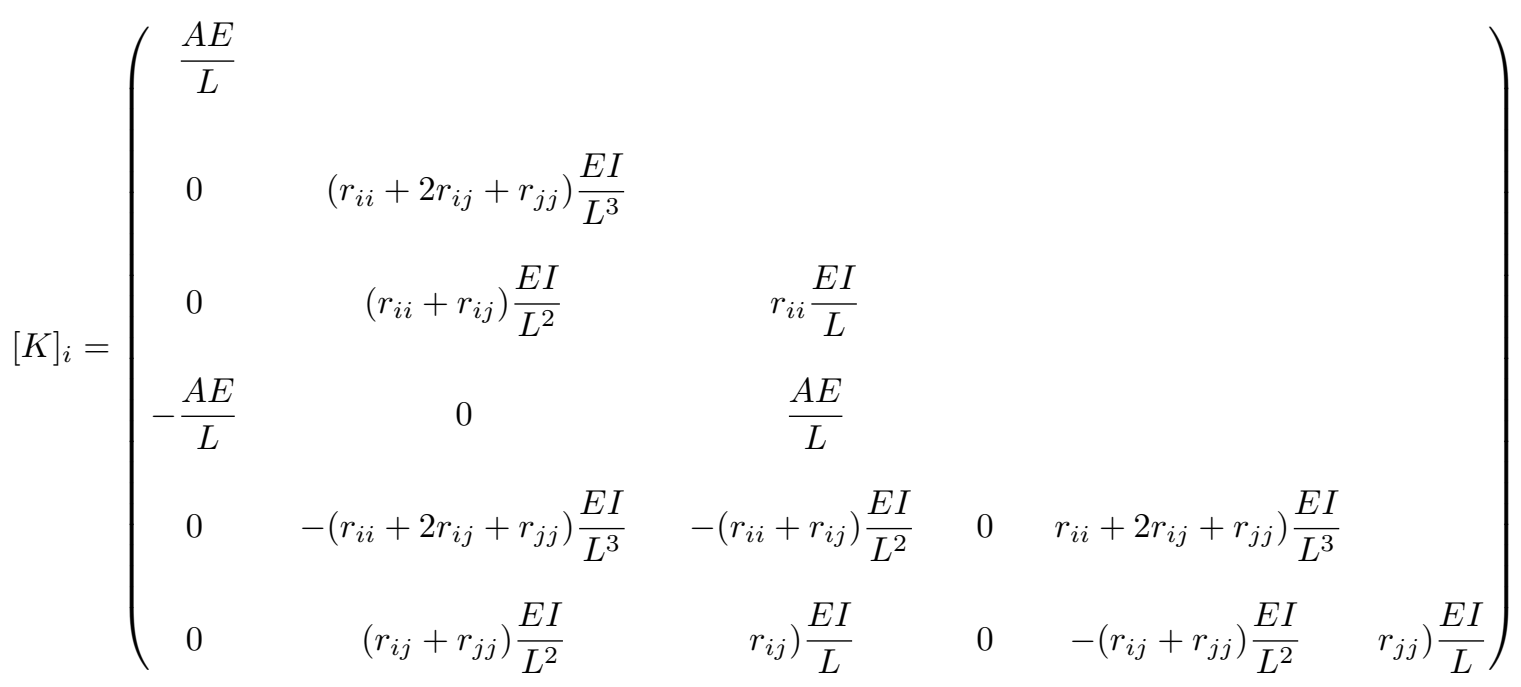

where $A$ is cross-sectional area of the member. Applying the known steps of the matrix displacement method, the above matrix is obtained in global coordinates or structure coordinates for each member and structure stiffness matrix is constituted. The relationships between end-forces and end-displacements are also constructed according to the same method. In the current work fixed-end forces which are derived in [110] are used for the beam members with semi-rigid end connections.

Table 4. Parameters values for various Models for Aluminum connection T18-1 \& T18-2

\begin{tabular}{lcccc}
\hline $\begin{array}{l}\text { Connection } \\
\text { Type }\end{array}$ & $\begin{array}{c}\text { Fan \& Adeoti Model } \\
\text { Quartic Polynomial Model) }\end{array}$ & $\begin{array}{c}\text { Frye \& Morris Model } \\
\text { (Odd power Polynomial Model) }\end{array}$ & $\begin{array}{c}\text { Kishi \& Chen Model } \\
\text { (3 Paremeters Power Model) }\end{array}$ & $\begin{array}{c}\text { Yee \& Melchers Model } \\
\text { (4 Paremeters Exp. Model) }\end{array}$ \\
\hline$C_{1}=1$ & $C_{1}=106.054$ & $n=2.18$ & $M_{P}=0.42$ \\
T18-1 & $C_{2}=2.5 \times 10^{-3}$ & $C_{2}=0$ & $K_{i}=12.59$ & $K_{i}=11.85$ \\
& $C_{3}=10^{-4}$ & $C_{3}=0$ & $M_{u}=0.51$ & $K_{P}=0.59$ \\
$C_{4}=10^{-6}$ & $K=9.43 \times 10^{-3}$ & -199.84 & - \\
\hline & $C_{5}=0$ & - & $n=2.03$ & $M_{P}=0.44$ \\
T18-2 & $C_{1}=1$ & $C_{1}=106.054$ & $K_{i}=11.72$ & $K_{i}=12.65$ \\
& $C_{2}=2.5 \times 10^{-3}$ & $C_{2}=0$ & $M_{u}=0.49$ & $K_{P}=0.41$ \\
& $C_{3}=10^{-4}$ & $C_{3}=0$ & $\theta_{r}=0.044$ & $C=81.57$ \\
& $C_{4}=10^{-6}$ & $K=9.43 \times 10^{-3}$ & - & - \\
\hline
\end{tabular}


Table 5. Parameters values for various Models for Aluminum connection T24-1 \& T24-2

\begin{tabular}{|c|c|c|c|c|}
\hline $\begin{array}{l}\text { Connection } \\
\text { Type }\end{array}$ & $\begin{array}{c}\text { Fan \& Adeoti Model } \\
\text { (Quartic Polynomial Model) }\end{array}$ & $\begin{array}{c}\text { Frye \& Morris Model } \\
\text { (Odd power Polynomial Model) }\end{array}$ & $\begin{array}{c}\text { Kishi \& Chen Model } \\
\text { (3 Paremeters Power Model) }\end{array}$ & $\begin{array}{c}\text { Yee \& Melchers Model } \\
\text { (4 Paremeters Exp. Model) }\end{array}$ \\
\hline T24-1 & $\begin{array}{c}C_{1}=1 \\
C_{2}=2.5 \times 10^{-3} \\
C_{3}=10^{-4} \\
C_{4}=10^{-6} \\
C_{5}=0\end{array}$ & $\begin{array}{c}C_{1}=106.054 \\
C_{2}=0 \\
C_{3}=0 \\
K=9.43 \times 10^{-3} \\
-\end{array}$ & $\begin{array}{c}n=2.35 \\
K_{i}=12.46 \\
M_{u}=0.53 \\
\theta_{r}=0.04 \\
-\end{array}$ & $\begin{array}{c}M_{P}=0.46 \\
K_{i}=12.48 \\
K_{P}=0.53 \\
C=162.04 \\
-\end{array}$ \\
\hline $\mathrm{T} 24-2$ & $\begin{array}{c}C_{1}=1 \\
C_{2}=2.5 \times 10^{-3} \\
C_{3}=10^{-4} \\
C_{4}=10^{-6} \\
C_{5}=0\end{array}$ & $\begin{array}{c}C_{1}=106.054 \\
C_{2}=0 \\
C_{3}=0 \\
K=9.43 \times 10^{-3} \\
-\end{array}$ & $\begin{array}{c}n=2.31 \\
K_{i}=11.05 \\
M_{u}=0.49 \\
\theta_{r}=0.045 \\
\quad-\end{array}$ & $\begin{array}{l}M_{P}=0.42 \\
K_{i}=11.22 \\
K_{P}=0.50 \\
C=133.04 \\
\quad-\end{array}$ \\
\hline
\end{tabular}

Table 6. Parameters values for various Models for Aluminum connection T30-1 \& T30-2

\begin{tabular}{lcccc}
\hline $\begin{array}{l}\text { Connection } \\
\text { Type }\end{array}$ & $\begin{array}{c}\text { Fan \& Adeoti Model } \\
\text { Quartic Polynomial Model) }\end{array}$ & $\begin{array}{c}\text { Frye \& Morris Model } \\
\text { (Odd power Polynomial Model) }\end{array}$ & $\begin{array}{c}\text { Kishi \& Chen Model } \\
\text { (3 Paremeters Power Model) }\end{array}$ & $\begin{array}{c}\text { Yee \& Melchers Model } \\
\text { (4 Paremeters Exp. Model) }\end{array}$ \\
\hline$C_{1}=1$ & $C_{1}=106.054$ & $n=1.87$ & $M_{P}=0.45$ \\
T30-1 & $C_{2}=2.5 \times 10^{-3}$ & $C_{2}=0$ & $K_{i}=16.67$ & $K_{i}=17.55$ \\
& $C_{3}=10^{-4}$ & $C_{3}=0$ & $M_{u}=0.54$ & $K_{P}=0.98$ \\
$C_{4}=10^{-6}$ & $K=9.43 \times 10^{-3}$ & $\theta_{r}=0.04$ & -162.26 \\
\hline$C_{5}=0$ & - & - & $M_{P}=0.39$ \\
T30-2 & $C_{1}=1$ & $C_{1}=106.054$ & $K_{i}=13.48$ & $K_{i}=12.52$ \\
& $C_{2}=2.5 \times 10^{-3}$ & $C_{2}=0$ & $M_{u}=0.49$ & $K_{P}=0.72$ \\
& $C_{3}=10^{-4}$ & $C_{3}=0$ & $\theta_{r}=0.037$ & $C=2.55$ \\
& $C_{4}=10^{-6}$ & $K=9.43 \times 10^{-3}$ & - & - \\
\hline
\end{tabular}

Table 7. Parameters values for various Models for Aluminum connection Test average Values

\begin{tabular}{|c|c|c|c|c|}
\hline $\begin{array}{l}\text { Connection } \\
\text { Type }\end{array}$ & $\begin{array}{c}\text { Fan \& Adeoti Model } \\
\text { (Quartic Polynomial Model) }\end{array}$ & $\begin{array}{c}\text { Frye \& Morris Model } \\
\text { (Odd power Polynomial Model) }\end{array}$ & $\begin{array}{c}\text { Kishi \& Chen Model } \\
\text { (3 Paremeters Power Model) }\end{array}$ & $\begin{array}{c}\text { Yee \& Melchers Model } \\
\text { (4 Paremeters Exp. Model) }\end{array}$ \\
\hline *T Av. H Dir. & $\begin{array}{c}C_{1}=1 \\
C_{2}=2.5 \times 10^{-3} \\
C_{3}=10^{-4} \\
C_{4}=10^{-6} \\
C_{5}=0\end{array}$ & $\begin{array}{c}C_{1}=106.054 \\
C_{2}=0 \\
C_{3}=0 \\
K=9.43 \times 10^{-3} \\
-\end{array}$ & $\begin{array}{c}n=1.81 \\
K_{i}=12.67 \\
M_{u}=0.53 \\
\theta_{r}=0.043 \\
-\end{array}$ & $\begin{array}{c}M_{P}=0.40 \\
K_{i}=12.90 \\
K_{P}=0.80 \\
C=119.33 \\
-\end{array}$ \\
\hline$* *$ T Av. V Dir. & $\begin{array}{c}C_{1}=1 \\
C_{2}=2.5 \times 10^{-3} \\
C_{3}=10^{-4} \\
C_{4}=10^{-6} \\
C_{5}=0\end{array}$ & $\begin{array}{c}C_{1}=106.054 \\
C_{2}=0 \\
C_{3}=0 \\
K=9.43 \times 10^{-3} \\
\quad-\end{array}$ & $\begin{array}{c}n=1.80 \\
K_{i}=12.13 \\
M_{u}=0.49 \\
\theta_{r}=0.043 \\
\quad-\end{array}$ & $\begin{array}{c}M_{P}=0.40 \\
K_{i}=12.62 \\
K_{P}=0.67 \\
C=94.54 \\
-\end{array}$ \\
\hline
\end{tabular}

*T Av. H Dir.: T18-1, T24-1 \& T30-1 connection test average values in the direction of the bolts.

**T Av. V Dir.: T18-2, T24-2 \& T30-2 connection test average values perpendicular to the direction of the bolts. 
Table 8. Parameters values for various models for Aluminum connection test average values irrespective of the direction of the bolts

\begin{tabular}{lcccc}
\hline $\begin{array}{l}\text { Connection } \\
\text { Type }\end{array}$ & $\begin{array}{c}\text { Fan \& Adeoti Model } \\
\text { (Quartic polynomial model) }\end{array}$ & $\begin{array}{c}\text { Frye \& Morris Model } \\
\text { (odd power polynomial model) }\end{array}$ & $\begin{array}{c}\text { Kishi \& Chen Model } \\
\text { (3 parameters power model) }\end{array}$ & $\begin{array}{c}\text { Yee \& Melchers Model } \\
\text { (4 parameters exponential Model) }\end{array}$ \\
\hline & $C_{1}=1$ & $C_{1}=106.054$ & $n=1.81$ & $M_{P}=0.40$ \\
*T Av. All Dir. & $C_{2}=2.5 \times 10^{-3}$ & $C_{2}=0$ & $K_{i}=12.67$ & $K_{i}=12.90$ \\
& $C_{3}=10^{-4}$ & $C_{3}=0$ & $M_{u}=0.51$ & $K_{P}=0.80$ \\
& $C_{4}=10^{-6}$ & $K=9.43 \times 10^{-3}$ & $\theta_{r}=0.043$ & - \\
\hline
\end{tabular}

*T Av. all Dir.: T18-1, T24-1 \& T30-1 and T18-2, T24-2 \& T30-2 connection test average values irrespective of the direction of the bolts.

Table 9. Parameters values for various models for Aluminum connection T1 \& T2

\begin{tabular}{lcccc}
\hline $\begin{array}{l}\text { Connection } \\
\text { Type }\end{array}$ & $\begin{array}{c}\text { Fan \& Adeoti Model } \\
\text { Quartic polynomial model) }\end{array}$ & $\begin{array}{c}\text { Frye \& Morris Model } \\
\text { (odd power polynomial model) }\end{array}$ & $\begin{array}{c}\text { Kishi \& Chen Model } \\
\text { (3 parameters power model) }\end{array}$ & $\begin{array}{c}\text { Yee \& Melchers Model } \\
\text { (4 parameters Exponential model) }\end{array}$ \\
\hline & $C_{1}=1.135$ & $C_{1}=105.95$ & $n=2.26$ & $M_{P}=0.36$ \\
$C_{2}=0.5$ & $C_{2}=100$ & $K_{i}=11.00$ & $K_{i}$ & $K_{P}=0.76$ \\
$\mathrm{~T} 1$ & $C_{3}=0.495$ & $C=344.88$ \\
& $C_{3}=0.5$ & $K=9.4 \times 10^{-3}$ & $\theta_{r}=0.0445$ & - \\
\hline$C_{4}=0.25$ & - & - & $M_{P}=1.99$ \\
T2 & $C_{5}=0$ & $C_{1}=105.95$ & $K_{i}=26.00$ \\
& $C_{1}=1$ & $C_{2}=100$ & $K_{i}=30.25$ & $K_{P}=1.20$ \\
& $C_{2}=0.004$ & $C_{3}=100$ & $M_{u}=2.226$ & $C_{r}=395$ \\
& $C_{3}=0.006$ & $-9.4 \times 10^{-3}$ & - & - \\
\hline
\end{tabular}

Table 10. Parameters values for various models for Aluminum connection $\mathrm{T} 3$ \& $\mathrm{T} 4$

\begin{tabular}{lcccc}
\hline $\begin{array}{l}\text { Connection } \\
\text { Type }\end{array}$ & $\begin{array}{c}\text { Fan \& Adeoti Model } \\
\text { Quartic polynomial model) }\end{array}$ & $\begin{array}{c}\text { Frye \& Morris Model } \\
\text { (odd power polynomial model) }\end{array}$ & $\begin{array}{c}\text { Kishi \& Chen Model } \\
\text { (3 paremeters power model) }\end{array}$ & $\begin{array}{c}\text { Yee \& Melchers Model } \\
\text { (4 paremeters Exponential model) }\end{array}$ \\
\hline & $C_{1}=1$ & $C_{1}=105.95$ & $n=2.15$ & $M_{P}=0.65$ \\
T3 & $C_{2}=0.07$ & $C_{2}=100$ & $K_{i}=34.00$ & $K_{i}=32.25$ \\
& $C_{3}=0.2$ & $C_{3}=100$ & $M_{u}=0.65$ & $K_{P}=0.10$ \\
& $C_{4}=0.15$ & $K=9.4 \times 10^{-3}$ & $\theta_{r}=0.02$ & - \\
\hline$C_{5}=0$ & - & - & $M_{P}=3.55$ \\
T4 & $C_{1}=1$ & $C_{1}=105.95$ & $K_{i}=2.96$ & $K_{P}=54.00$ \\
& $C_{2}=0.07$ & $C_{2}=100$ & $M_{u}=3.626$ & $K_{P}=0.13$ \\
& $C_{3}=0.028$ & $C_{3}=100$ & $\theta_{r}=0.07$ & - \\
& $C_{4}=0.002$ & $K=9.4 \times 10^{-3}$ & - & - \\
\hline
\end{tabular}

